\title{
Indios originarios y forasteros. Interacciones culturales y cambios demográficos en los Altos de Arica y Tacna (siglos XVI y XVIII)
}

\section{Native indians and outsiders. Cultural interactions and demographic changes in the Arica and Tacna highlands (XVI and XVIII centuries)}

\author{
Carlos Choque Mariño ${ }^{1}$ https://orcid.org/0000-0002-4743-4864 \\ ${ }^{1}$ Departamento de Ciencias Históricas y Geográficas, Universidad de Tarapacá, Arica, CHILE. \\ E-Mail: cochoquem@uta.cl
}

\begin{abstract}
Resumen
El presente artículo analiza las interacciones culturales y cambios demográficos de las poblaciones indígenas en los Altos de Arica y Tacna. Examina la composición vegetativa, identidades culturales y cargas tributarias de indios originarios y forasteros del territorio de estudio. El resultado de tales indagaciones devela la supremacía de poblaciones locales en oasis y valles interandinos, situación que se constata en revisitas y tasas de tributos. Asimismo, se evidencia una taxonomía de originarios/ forasteros con tensiones culturales y políticas, que llevaron a los migrantes indígenas a desarrollar una adscripción y naturalización cultural mediante las relaciones de parentesco y afiliaciones rituales con comunidades y cacicazgos costeros en los siglos XVI y XVIII (1540-1600 y 1680-1793).
\end{abstract}

Palabras claves: Arica y Tacna, indios, interacciones culturales, demografía, tributos.

\begin{abstract}
This article analyzes the cultural interactions and demographic changes of indigenous populations in the Arica and Tacna Highlands. In doing so, it examines the vegetative composition, cultural identities and tax burdens of native Indians and outsiders in the study territory. The result of such inquiries reveals the supremacy of local populations in oases and inter-Andean valleys, a situation that can be seen in revisits and tax rates. Likewise, there is evidence of a taxonomy of natives/forestry with cultural and political tensions, which led the indigenous migrants to develop a cultural ascription and naturalization through kinship relations and ritual affiliations with communities and coastal chiefdoms in the XVI and XVIII centuries (1540-1600 and 1680-1793).
\end{abstract}

Keywords: Arica and Tacna, Indians, cultural interactions, demography, tributes.

Recibido: 13 julio 2018. Aceptado: 15 marzo 2019 


\section{Introducción}

En 1538 Arica y Tacna comenzaron a participar de las dinámicas económicas, socioculturales y políticas que se originaron con la conquista hispana e implementación de la encomienda indiana (Trelles, 1991; Hidalgo, 2004; Glave y Díaz, 2019). Más tarde, la jurisdicción tuvo una marcada vinculación con la economía minera de Charcas (Cañedo-Argüelles, 1993; Presta, 2008; Gavira, 2010; Platt y Quisbert, 2010; Choque y Muñoz, 2016; Larson, 2017). El desarrollo de las actividades extractivas en Porco, Potosí o Carangas requirieron de una abundante mano de obra indígena como también de productos indianos, manufacturas y animales (Assadourian, 1982, 1989; Tandeter y Wachtel, 1983; Apey, 1990), generando con ello una serie de cambios en las poblaciones de los diversos grupos étnicos del área centro-sur andina. Por consiguiente, numerosos estudios han buscado comprender las transformaciones y evolución demográfica en los Andes (Wightman 1990; Wachtel, 1992; Charney, 2001; Cook, 2002, 2005, 2010; Robinson, 2006; Livi Bacci, 2007; Saito y Rosas, 2017) y en Chile, los análisis se han enfocado en los archivos parroquiales y registros censales del área andina (Hidalgo, 1978; Hidalgo y Focacci, 1986; Hidalgo et al., 1988, 2004b; Durston e Hidalgo, 1997; Ruz et al., 2008; Inostroza, 2013).

Las fuentes etnohistóricas del siglo XVI describen la composición étnica de valles y altos del Corregimiento de Arica, que estuvo integrada por "pescadores" y "agricultores" yungas, que comparten el mismo legado cultural, concepciones ideológicas y estructuras organizacionales duales (Muñoz, 1989; Durston e Hidalgo, 1997; Horta, 2010, 2011; Muńoz y Choque, 2013). Asimismo, documentos y datos arqueológicos sostienen que dichas sociedades poseyeron una autosuficiencia económica y política desde el Intermedio Tardío (Horta y Agüero, 2009; Horta, 2013), y más tarde, integradas a las zonas de influencia de los reinos altiplánicos e incas, cuyas estrategias de dominio fueron la movilización de colonias o mittanis, ${ }^{1}$ que constituyeron enclaves productivos de carácter "estacional o permanente"

1 Concepto aymara, equivalente al término colonial de "mitimaes".

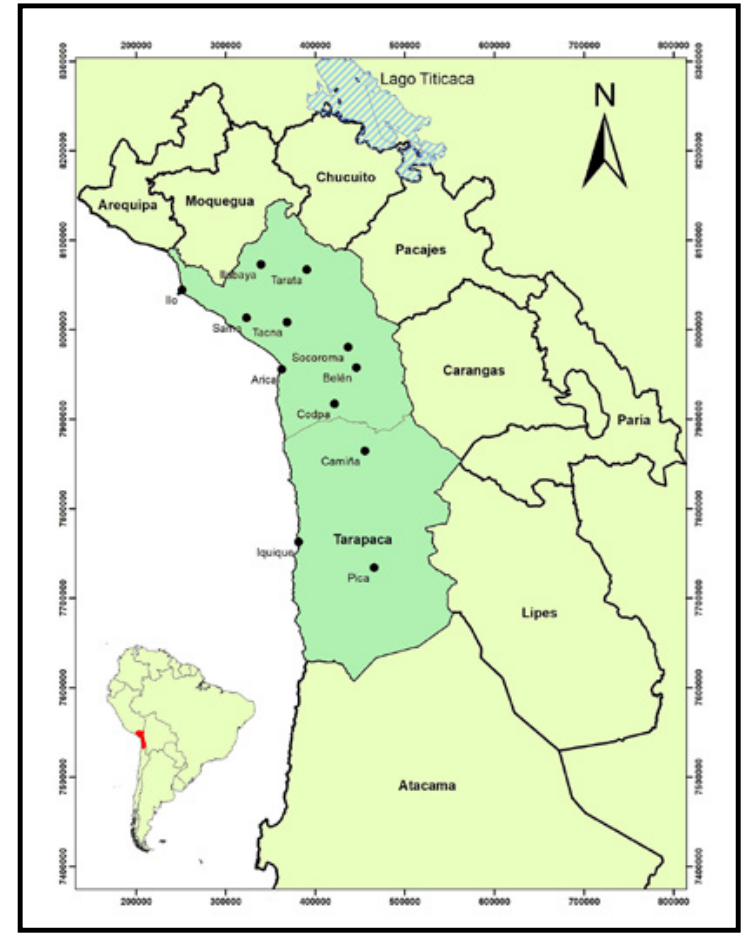

Figura 1. Corregimiento de Arica entre 1565 y 1768.

(Murra, 1972, p. 191). ${ }^{2}$ Más tarde, el territorio se convirtió en corregimiento por la Real Cédula de 1565 e incluyó las zonas de Tarapacá, Tacna y Arica (Figura 1). ${ }^{3}$

La configuración colonial del indio originario y forastero $^{4}$ se atribuye a los postulados y ordenanzas del virrey Francisco de Toledo, quien ejecutó las instrucciones de Felipe II en los Andes. ${ }^{5}$ Sobre la calidad de los indios, Isabel Castro y Silvia

2 John Murra advierte, sin embargo, que los cronistas europeos llaman mitmaq o mittanis a todo aquel que residía lejos de su tierra natal, pues pudieron ser "agricultores o guerreros" (Murra, 1964, p. 428).

3 En 1768 la zona de Tarapacá es separada del Corregimiento de Arica, constituyendo una nueva unidad administrativa. Debe precisarse que el espacio de estudio corresponde a los repartimientos de Ilo, Hilabaya, Ite, Tacna, Tarata, Sama, Lluta, Arica y Codpa.

4 Otras categorías empleadas fueron la, agregados o yanaconas. Además, existieron las castas de mestizos, castizos, zambos, mulatos, moriscos, saltatrás o tornatrás, cholos, harnizos y chamizos, entre otros.

5 La Junta estableció un criterio, de forma que ni los indios dejaran de pagar lo que se considera justo, ni tampoco fueran cargados con exceso. 
Palomeque explican que los "originarios" son tributarios de pueblos de indios y sujetos a sus autoridades indígenas, ${ }^{6}$ que pagan tributos y participan de la mita; y los "forasteros" son aquellos originarios que abandonaron sus pueblos de reducción u origen y se radicaron en otros lugares (Hidalgo, 1984b; Hampe, 1985; Serulnikov, 2003; Sanhueza, 2008; Escobari, 2012; Castro y Palomeque, 2016; Tell y Castro, 2016; Saldarriaga, 2017). ${ }^{8}$ Situación que fue particularmente compleja en algunos repartimientos de Arequipa, pues el tributo que pagaban los indios, según Jürgen Golte, "estaba por encima del promedio del virreinato" (Golte, 1980, p. 35), obligando a los indios a trabajar en pueblos distantes para pagar la contribución. Sin embargo, también el abandono de las comunidades y reducciones, según Raquel Gil Montero, se debió principalmente a la evasión de las obligaciones fiscales de los indígenas (Gil Montero, 2014). La condición de indio originario se sustenta, según Sonia Tell e Isabel Castro, en la existencia de un régimen de usufructo de la tierra acordado entre la Corona y los indios. Los últimos aceptaron la obligación de responder a la carga tributaria impuesta. Sin embargo, los cambios demográficos, el establecimiento de las reducciones indígenas y la severa explotación de la población indígena en algunas regiones andinas reconfiguraron permanentemente las tasas del tributo (Casassas, 1974; Larraín, 1974; Watanabe et al., 1990; Cook, 2010; Morrone, 2017; Saito y Rosas, 2017).

Si bien, el examen estadístico de las poblaciones andinas posee complejidades metodológicas, tanto por el alcance de la información como por el método y temporalidad, tiene a su favor la delimitación territorial, que permite un estudio focalizado en ciertas áreas de interés. $\mathrm{Al}$ respecto, Noble David Cook sugiere utilizar materiales fiscales, ya que cuantifican a

6 En su estudio de la visita de Garci Diez de San Miguel a Chucuito, Waldemar Espinosa Soriano establece que el tributario era un varón adulto casado, con su propia casa y campos.

7 Las Ordenanzas Toledanas establecen que nadie podía abandonar la tierra donde estaba reducido y contabilizado.

8 En otras regiones de los Andes, los indios forasteros tenían como principal motivación el acceso a productos que eran inexistentes antes de la conquista hispana, tales como vino, miel y guarapo en la Nueva Granada (Saldarriaga, 2017). tributarios, mujeres, nińos y ancianos, cuyos primeros antecedentes se expresaron en las cédulas de encomiendas y tasas pretoledanas (Cook, 2010). ${ }^{9}$ Más tarde, la realización de censos manuscritos agregó información relativa a la edad, sexo, ayllus y recursos disponibles de cada aldea censada. La ausencia de registros parroquiales tempranos hace inviable un cotejo de este tipo de información, ya que es aislada y la documentación existente para Arica es posterior a 1650. También existe escasez de visitas generales y eclesiásticas para gran parte del siglo XVII. Los historiadores Jorge Hidalgo, Nelson Castro y Soledad González proponen un análisis comparativo de unidades censales, considerado un método que permite conocer las composiciones demográficas, economías y organización política del territorio (Hidalgo et al., 2004b). De esta manera, la identificación de distintas categorías del "indio" permite establecer diferenciaciones de tributarios originarios, forasteros, autoridades, reservados y mujeres, entre otros, según los criterios de la reorganización toledana y los instrumentos censales y fiscales empleados en la época. Si bien el análisis implica el uso de fuentes imperiales y codificaciones de la época, estas constituyen las únicas fuentes de datos demográficos disponibles para la investigación. Las clasificaciones de indios tributarios ya habían sido probadas previamente, $y$ configuraban una parte sustantiva de las revisitas, tal como se observa en la visita de Garci Diez de San Miguel en Chucuito. ${ }^{10}$ La presente investigación no buscó la realización de extrapolaciones demográficas, sino utilizar los datos cuantitativos documentados en

9 La existencia de un período pretoledano y toledano, desde una perspectiva política y administrativa, es tratada en los trabajos de Guillermo Lohmann Villena (1967), Juan Carlos Estenssoro (2003) y José Luis Martínez (2012).

10 "Luego haréis padrón de todos los indios e indias y muchachos que en cada pueblo y parcialidad hobiere poniéndolos por sus nombres y escribiendo las edades que tienen y al fin de la visita de cada pueblo sacaréis por relación los indios casados a una parte y los solteros y viudas a otra y los muchachos y viejos por el consiguiente y asimismo pornéis por memoria los indios de dicha provincia que anduvieren fuera de ella entendiendo en algunos tratos y granjerías o estuvieren en algunos asientos". En foja 3v. Archivo General de Indias (en adelante AGI), Justicia 479, "Visita hecha a los indios de la provincia de Chiquitos, por Garci Díez de San Miguel, Juez nombrado para este efecto”, fojas 1r-142r. 
cédulas de encomiendas y visita general de Francisco de Toledo en Arica y Tacna para el siglo XVI. Desde otra perspectiva, el siglo XVIII es examinado a través de los registros censales de 1750, 1772 y 1793, que evidencian las estructuras sociales y etarias, categorías fiscales y adscripciones culturales de las poblaciones indígenas.

En consecuencia, se plantean las siguientes interrogantes: ¿Qué antecedentes o enfoques analíticos permiten comprender las configuraciones y filiaciones demográficas de los indios de Arica y Tacna para el siglo XVI? ¿Cuáles fueron las expresiones de continuidad cultural e interacciones socioeconómicas en las poblaciones del Corregimiento de Arica a fines del siglo XVII? ${ }^{11}$ ¿Fueron las revisitas coloniales de los siglos XVII y XVIII un instrumento que permitió la construcción y distinción cultural entre las poblaciones originarias y forasteras?

La circulación y movilidad de mano de obra indígena local se dinamizó aún más, según Horario Larraín y José María Casassas, por la demanda de nuevos productos agropecuarios, manufacturas y oficios calificados en Potosí, Porco, Carangas o La Plata. También trajo consigo la llegada de mitayos, esclavos o capataces especializados para mercado minero. En este sentido, la hipótesis tiene en consideración que las reformas toledanas y borbónicas establecieron nociones jurídicas y económicas del indio originario y forastero, permitiendo la configuración de nuevas otredades y tensiones en las identidades locales y forasteras. De igual modo, el binomio originario/forastero constituyó una frontera cultural, económica y política, que dio como resultado un sistema jerarquizado bidireccional, que consolidó identidades y prestigio local-originario a medida que se realizaban las revisitas coloniales y censos republicanos, cuyo producto fue la naturalización

11 La antropología sostiene que la "continuidad cultural", la capacidad creadora que conserva, renueva y acumula innovación sobre innovación cultural, así las culturas mantienen su continuidad a partir de sus propios pensamientos, conductas y significados, pero no están eximidas del proceso de evolución. En este sentido, la vigencia de ciertos ritos agrícolas y pastoriles e identidades está regida por sus propios procesos de cambios y rupturas que pueden haberse originado por diversos factores externos a su propia realidad. cultural de los afuerinos mediante las relaciones de parentesco, compadrazgo y afiliaciones rituales con comunidades y cacicazgos del espacio territorial de Arica y Tacna en los siglos XVI y XVIII. Finalmente, el examen desea abordar ciertos espacios temporales del período colonial (1540-1600 y 1680-1793), dada la ausencia de materiales que permitan abordar de manera continua la investigación.

\section{Configuraciones y filiaciones étnicas en Arica y Tacna entre los ańos 1540 y $1600^{12}$}

Las primeras noticias sobre los valles de Arica y Tacna se conocieron tempranamente, en 1534, con Diego de Agüero y Pedro Martín de Moguer, quienes recibieron informes del territorio gracias a los testimonios de los seńores principales de Chucuito (Cavagnaro, 1988). Más tarde, el capitán Rui Díaz, siguiendo la expedición de Diego de Almagro, pasó por Arica y se enfrentó a los indios camanchacas en 1536. Del mismo modo, Almagro en su retorno de Chile atravesó el territorio, realizando el primer registro documental de las capacidades productivas y demográficas de la región.

La historiadora Katherine Julien señala que las poblaciones locales o yungas estuvieron integradas por indios camanchacas y coles; ${ }^{13}$ los primeros, pescadores; los segundos, agricultores (Julien, 1979). Siete años más tarde, María Rostworowski sostuvo que estos indios yungas no solo estuvieron instalados en las costas y valles, sino también en las serranías del territorio, pues fue posible identificarlos al interior de Moquegua y Tarata, y por ende también en los Altos de Arica (Rostworowski, 1986; Cañedo-Argüelles,2005; Horta, 2011; Choque y Pizarro, 2012;

12 Las páginas siguientes exponen transcripciones textuales de documentos históricos de los siglos XVI y XVIII, incluidos a pie de página que permiten explicar y complementar el análisis del corpus del artículo. La omisión de tales antecedentes puede plantear dudas o cuestionamientos para un lector no especializado en los temas etnohistóricos de los Andes chilenos.

13 Los estudios de Francisco Rothhammer (2010) y su equipo expresan que los camanchacas fueron llamados también como "Proanches" o "Changos", y que compartieron el espacio ecológico con colonias de "Urus" altiplánicos. 
Muñoz y Choque, 2013). Respecto a la lengua común de estos indios yungas, Guillermo Galdos (1982), Jorge Hidalgo y Guillermo Focacci (1986), Alfredo Torero (1987) y Rodolfo Cerrón-Palominos (2011) han propuesto que los grupos étnicos locales hablaron el puquina. ${ }^{14}$ Una situación análoga se presenta en la meseta altiplánica durante el siglo XVI, donde Alfredo Torero identificó un panorama idiomático diverso, dado que los señoríos del Collao y Charcas usaron las lenguas: "aymara, quechua, puquina y uruquilla” (Torero, 1987, p. 329). Adicionalmente, Helena Horta expresa que las fuentes etnohistóricas "mencionan población de la subárea altiplano meridional pacaje y caranga cohabitando con la población local de los oasis costeros" (Horta, 2011, p. 253).

El 22 de enero de 1540 se dictó una cédula de encomienda que fracciona el territorio entregado en 1538 a Pedro Pizarro, quien recibió en la nueva cédula el valle de Tacna, Curane y sus diversos pagos ubicados en Arica y Tarapacá. Una parte menor fue adjudicada a Hernando de Torres y otra porción de mayor tamaño a Lucas Martínez de Vegazo. Igualmente, una menor cantidad de indios fue entregada en Sama e Hilabaya a Hernando Rodríguez de Huelva y Juan de San Juan. Por otra parte, también hubo repartimientos de indios en las costas de Arica y Tacna, que beneficiaron a Lope de Mendieta en Carangas y al propio emperador Carlos V, quien tuvo la Encomienda Real de Chucuito, cuyos indios residían en esta jurisdicción. ${ }^{15}$

El sistema de encomiendas no hizo distinción entre las poblaciones locales y colonos altiplánicos, ya que en dicha década no hubo tasas ni ordenanzas que reglamentaran el trabajo indígena, tributo, y menos la filiación étnica. En otras palabras, los encomenderos

14 Esta lengua se usaba en diversas regiones y en el altiplano ocupó los mismos espacios con los aymara hablantes y quechua hablantes, según los análisis de Katherine Julien (1983). Postura similar tiene Bente Bittmann (1984), quien sostiene que los pescadores tuvieron lengua propia.

15 Archivo General de Indias (en adelante AGI), Justicia 479, "Visita hecha a los indios de la provincia...", f. 63r. La visita de Garci Diez de San Miguel informa que los señores de Chucuito tuvieron en 1567 unos 382 indios en condición de mittanis entre Sama y Moquegua. de Arica y Tacna recibieron un mosaico étnico integrado por poblaciones yungas y mittanis de origen lupaca, pacajes y carangas, que siguieron conservando una dependencia política y cultural con sus comunidades de origen (Choque, 2009, 2015; Horta, 2011). ${ }^{16}$ Dicha expresión de multietnicidad, según Alan Durston y Jorge Hidalgo, tiene como característica principal las sucesivas y simultáneas ocupaciones culturales y económicas de los archipiélagos ecológicos que fueron realizadas por las poblaciones yungas y forasteras (Durston e Hidalgo, 1997).

El gobernador Francisco Pizarro favoreció enormemente a Lucas Martínez de Vegazo en comparación a otros encomenderos, que recibieron cantidades inferiores de indios tributarios (Figura 2). La entrega de esta cuantiosa encomienda genera dos hipotéticas respuestas según Efraín Trelles; la primera sostiene que se le otorgó una enorme jurisdicción debido a la estima que le tuvo el marqués; la segunda postula que Pizarro no dimensionó el tamaño ni cantidad de indios que estaba otorgando al encomendero trujillano.

Además, la cédula establece que Lucas Martínez de Vegazo recibió 1.638 tributarios, Pedro Pizarro 800 y Hernando de Torres unos 600 indios. ${ }^{17} \mathrm{Si}$ bien diversas fuentes y estudios plantean algunas diferencias en las cantidades de indios tributarios, estas cifras son poco significativas y no inciden en el análisis global de situación demográfica del territorio en 1540 (Figura 3). La composición étnica de las poblaciones indígenas desde Ilo a Codpa fue compleja, pues se trató de un espacio salpicado por "distintos grupos étnicos y poderes políticos" (Hidalgo, 2004, p. 443).

Las indagaciones permiten establecer preliminarmente, sin considerar los indios de la encomienda de Juan de San Juan en Hilabaya y Sama, que hubo

16 Helena Horta sostiene que existió un primer nivel entre dos grupos (uno de ellos identificado como pacaje), y en un segundo nivel, los carangas, que se ubicaron en los valles costeros de Azapa, Lluta y Vítor, y por otra, en la costa misma.

17 AGI, Justicia 401, N 1, "Lucas Martínez contra herederos de Jerónimo de Villegas", fs. 1r-1616v. Pedro de la Fuente recibió 800 indios; Diego Hernández, 593, y Martín López de Carvajal, 287. AGI, Justicia 401, $\mathrm{N}^{\circ}$ 1, "Lucas Martínez contra herederos de Jerónimo de Villegas", fs. 1r-1616v. 


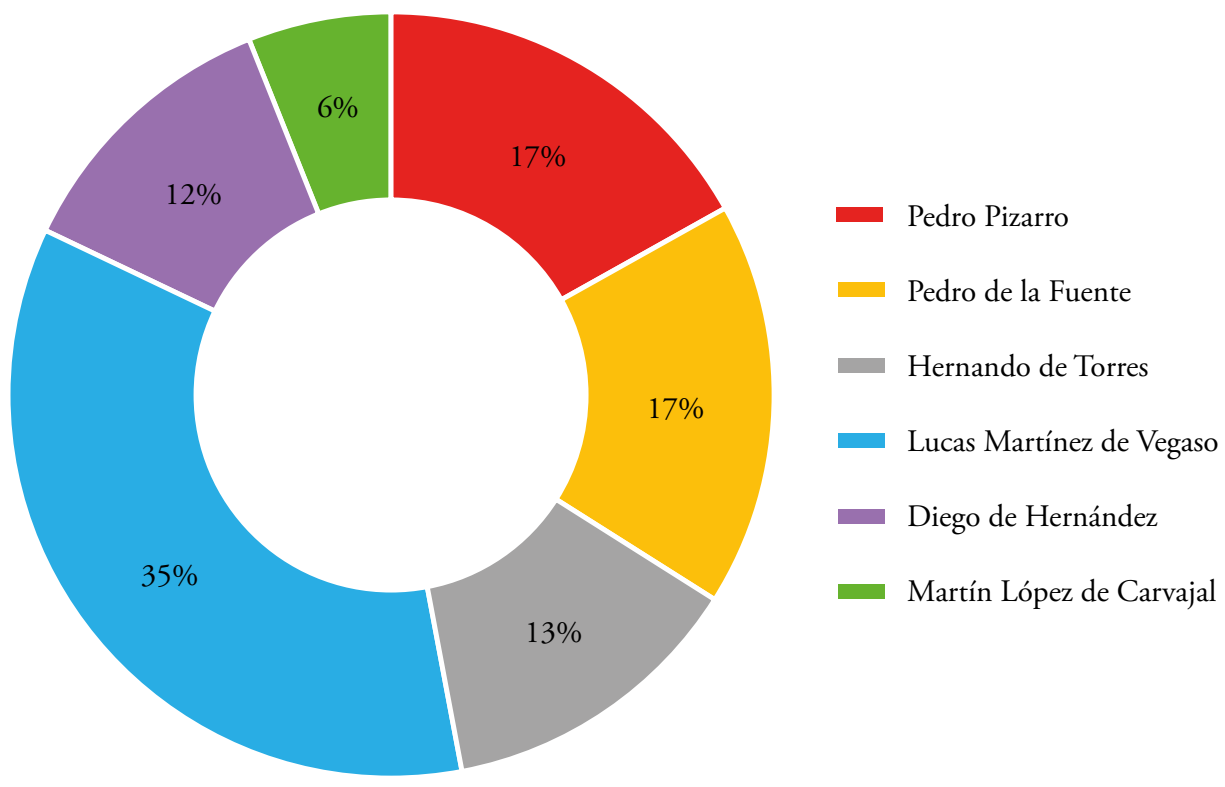

Figura 2. Comparación de porcentajes de indios tributarios asignados en las cédulas del mes de enero en 1540.



Figura 3. Espacio yunga y principales centros políticos de la costa y altiplano del siglo XVI. 
Tabla 1. Agricultores, pescadores y mittanis en las encomiendas de Arica y Tacna de $1540 .^{21}$

\begin{tabular}{|l|c|c|c|c|}
\hline & Agricultores & Pescadores & Mittanis & Total \\
\hline Lucas Martínez de Vegazo & 200 & 194 & 244 & 638 \\
\hline Pedro Pizarro & 800 & 41 & 40 & 881 \\
\hline Hernando de Torres & 600 & - & - & 600 \\
\hline Hernán Rodríguez de Huelva & 299 & - & - & 299 \\
\hline Lope de Mendieta & 111 & 26 & 42 & 149 \\
\hline Encomienda Real de Chucuito & - & - & 465 & 465 \\
\hline Totales & 2010 & 261 & 761 & 3032 \\
\hline
\end{tabular}

entre Arica y Tacna 2.010 tributarios yungas, 261 pescadores y 761 colonos que deben contribuir a la Corona según las instrucciones de la emperatrizregente, doña Isabel de Portugal (Tabla 1), ${ }^{18}$ identificándose un $66 \%$ de tributarios de origen local y los demás, mittanis y pescadores (Figura 4). ${ }^{19} \mathrm{La}$ filiación de estos últimos es compleja, ya que los documentos no afirman o rechazan una procedencia local o forastera de dichos indios. ${ }^{20}$ En vista de los antecedentes expuestos, cabe la interrogante: ¿Es posible identificar el origen parcial de los mittanis

18 Recopilación de Leyes de los Reynos de las Indias, Libro VI, Título V, Ley IV, p. 339, "Que tributen los indios mitimaes que antes tributaban”. El emperador Don Carlos y la emperatriz gobernadora en Madrid a 18 de octubre de 1539. En algunos pueblos del Perú, encomendados y tasados, residen los indios, llamados mitimaes, que en tiempo de su gentilidad andaban, servían, y contribuían juntos con sus caciques, y principales, y despues se escusaban de servir, diciendo que no eran naturales de la tierra, y se vinieron á vivir de otras partes. Y porque si se les permitiese recibirían daño los demas indios, y recaería el servicio, que antes hacían todos en estos solos, quedando libres los mitimaes, sin embargo de que gozan de los beneficios, y aprovechamientos de la tierra, y su vecindad, mandamos, que si es asi, que los mitimaes han servido y contribuido á los que dominaban, sean compelidos, y apremiados á que juntamente con los caciques, y principales, contribuyan en los pueblos donde habitan, lo que estuviere tasado, a sus encomenderos, sin escusa".

19 Un análisis similar fue realizado por Helena Horta (2010), quien identificó en las encomiendas de Lucas Martínez de Vegazo y Lope de Mendieta a 168 mitimaes en Arica y Azapa.

20 Cecilia Sanhueza en su estudio sobre los indios de la puna de Atacama en el siglo XVIII identifica proporciones similares de originarios y forasteros, puesto que los primeros configuran el " $74 \%$ de la población en promedio” (Sanhueza, 2008, p. 208). emplazados en los Altos de Arica? Los estudios de Hidalgo y Focacci (1986), Julien (1979), Larraín (1974), Murra (1972, 2002) y Rivière (1982) proporcionaron datos sobre la presencia de las colonias altiplánicas en los valles de Azapa, Lluta, Codpa, Sama o Locumba, relativos a los primeros ańos del dominio hispano. Sin embargo, los antecedentes expuestos por Gilles Rivière (1982) también sostienen que los carangas fueron desprovistos de estos archipiélagos costeros ya para el siglo XVI.

Los antecedentes judiciales expuestos por dońa María de Dávalos contra Gonzalo de Valencia sostienen que a mediados del siglo XVI la población local tenía por señor principal de Arica a don Juan Tauqui, quien poseía sus pagos en Umagata, Lluta, Ocurica y playas de Arica. ${ }^{22}$ También, los pleitos de Lope

21 Para el caso de Lucas Martínez de Vegazo, ver: Archivo General de la Nación del Perú (En adelante AGN), Fondo Campesinado, Legajo 2, Cuaderno 15, "Restitución de tierras en Ilo, Arica y Tarapacá de la encomienda de Lucas Martínez Vegazo”, fs. 255v-264r; Para uno de los encomenderos de Hilabaya, Hernán Rodríguez de Huelva, ver Víctor Barriga, 1940, pp. 203-204; Antecedentes de Hernando de Torres están consignados en Cavagnaro, 1988, pp. 32-34; La cantidad de indios tributarios de Lope de Mendieta en el Corregimiento de Arica, se encuentra consignada en: AGI, Justicia 658, $\mathrm{N}^{\circ}$ 2, "El fiscal contra Antonio Álvarez, vecino de la Ciudad de la Plata sobre el derecho a la encomienda de Guachacalla”, fs. 474r-1238r; La cédula de encomienda de Pedro Pizarro se puede observar en: AGI, Justicia 401, $\mathrm{N}^{\circ} 1$, "Lucas Martínez contra herederos de Jerónimo de Villegas", fs. 341v-342r; la Encomienda Real de Chucuito no consigna antecedentes para el año 1540 , por tanto se considera para la tabla los datos ofrecidos en la Visita General de Toledo. Ver Cook, 1975, pp. 79-80.

22 AGN, Legajo 2, Cuaderno 15, "Restitución de tierras en Ilo, Arica y Tarapacá de la encomienda de Lucas 




Figura 4. Distribución porcentual de indios para la década de 1540.

de Mendieta con Antonio Álvarez por los indios de Guachacalla ${ }^{23}$ permiten identificar que dichos carangas poseían indios mittanis en los valles costeros ubicados a unas 20 leguas de Corquemarca o Sabaya. ${ }^{24} \mathrm{Al}$ respecto, el "Memorial de los Charcas"

Martínez Vegazo”, f. 260v. La causa entre los herederos de Lucas Martínez con Gonzalo de Valencia señala que "don juan cacique principal señor de humagata en los valles de arica e yuta e caxa e ocorica de los pescadores que están en la costa de arica e cayacaya e chaco y los churos questan en los del poblado e a vos chura y guaviña e chuquianca e vilcas e ota e calla prenzipales e a los demás caciques principales e indios vuestros subjetos que al presente soys e despues de vos subcedieren en el rrepartimyento de arica e los valles".

23 AGI, Justicia 658, N² 2, "El fiscal contra Antonio Álvarez, vecino de la Ciudad de la Plata sobre el derecho a la encomienda de Guachacalla”, fs. 474r-1238r.

24 AGI, Justicia 658, Nº 2, "El fiscal contra Antonio Álvarez, vecino de la Ciudad de la Plata sobre el derecho a la encomienda de Guachacalla", f. 1219r. "Yndios de la encomyenda del dicho Lope de Mendieta porque estan algunos pueblos desviados unos de otros a veynte e a veynte e cinco leguas e a diez e menos y que como dicho tiene son distintos los unos de los otros e esto sabe porque como cura que a sido y es este testigo de las encomyendas a visitado e bisita los dichos pueblos e parcialidades e si otra cosa fuese este testigo lo abria visto y establece que los carangas y quillacas poseen "muchas tierras y chacras calientes y estancias de buenos temples en muchas partes", ${ }^{25}$ y no son pobres como alegaron ante el virrey Francisco de Toledo, según la declaración del principal de los Charcas, don Fernando Ayaviri y Velasco (Horta, 2009). En la misma época del pleito entre Antonio Álvarez y Lope de Mendieta, este último también se enfrentó a Lucas Martínez de Vegazo por el control de dichos colonos en las costas de Arica y Tacna. ${ }^{26} \mathrm{~A}$ la par, los lupacas controlaron tierras en los valles de occidentales para la producción de maíz y chuño, que eran "transportados por los indios de servicio a Chucuito" (Glave, 2000, p. 394). ${ }^{27}$ No obstante, no

entendido y que en lo demas se remyte este testigo a los dichos títulos de encomyendas de indios".

25 AGI, Charcas 45, "El memorial de los Charcas", fs. 1r$31 \mathrm{v}$.

26 AGI, Justicia 401, N² 2, "Relación sacada de la probanza presentada por Lucas Martínez en grado de suplicación", f. 35r.

27 AGI, Justicia 479, "Visita hecha a los indios de la provincia...”, f. 7v. Los lupacas en la visita de 1567 informan también que sus indios de la costa se alquilan "[...] con los españoles para cargar carneros con coca a Potosí y para cargar mercaderías desde el puerto de Arica y 
existe claridad sobre la proporcionalidad de esta población de residencia temporal o permanente, que según Garci Diez de San Miguel para el caso lupaca en 1567 , tuvieron cerca de un millar de mittanis en los yungas de la costa (Murra, 2002).

Los registros de población en las primeras décadas de presencia hispana son infrecuentes e incompletos. Noble David Cook, teniendo en consideración la existencia de los 3.032 indios tributarios y la aplicación de un ratio de 5.1 propuesto por Trelles y Cook, estima una cantidad de 15.463 personas, sin considerar su adscripción originaria y forastera.

Durante la segunda mitad del siglo XVI a los cambios políticos, económicos y socioculturales se le sumó el demográfico. El impacto del sistema de explotación económica que se aplicó a la población indígena con las encomiendas generó un descenso en la población de un 36\% entre 1540 y 1570 . Este descenso además fue generado por las huidas y enfermedades que afectaron principalmente a los indios en condiciones de tributar, hecho que llevó a Trelles a afirmar que la expectativa de vida era muy baja, en especial en la costa (Trelles, 1991; Muñoz y Choque, 2013). Los cambios demográficos fueron más evidentes en la costa sur del Perú colonial, pues a la existencia de las enfermedades, se le sumaron los terremotos y prolongadas sequias y hambrunas, que crearon una elevada tasa de despoblación indígena Choque y Pizarro, 2009; Cook, 2010)..$^{28}$ En términos estadísticos la disminución de la población fue de $-3,8 \%$ en la costa y $-1,1 \%$ en la sierra, hecho que aceleró, además, el despojo de tierras a los indios de la costa de Arica (Hidalgo y Focacci, 1986; Herrera, 1997). Simultáneamente, el territorio se estaba reorganizando en el Corregimiento de Arica y, a su vez, los primeros asentamientos hispanos no se limitaron al puerto de Arica, Tacna o la Quiaca, sino que buscaron territorios más cálidos como los cursos medios de los valles, presionando sobre los espacios productivos indígenas.

desde el puerto de Ilo [...]".

28 En este sombrío contexto, Cook sostiene que en algunas regiones andinas los fallecimientos originados por las epidemias generaron una mortandad de 17 a $20 \%$ de la población local.
Finalmente, hacia 1570 el virrey Francisco de Toledo dictó un conjunto de ordenanzas que van a cambiar radicalmente la vida de los indígenas, redistribuyendo el territorio con las reducciones y doctrinas de indios, buscando con ello dar un mayor impulso al control hacendístico de la población y organización de levas de "mitayos" para los obrajes, ingenios, haciendas y minas de plata y mercurio del virreinato (Martínez, 2012; Merluzzi, 2014). De esta forma, las reducciones de indios se constituyeron en la mayor expresión de los cambios demográficos a gran escala, según Manfredi Merluzzi, quien expresa que fue una política de éxodo forzado de la población a otros núcleos urbanos. Además, los nuevos asentamientos se constituyeron como espacios de articulación y negociación política, circulación de bienes y cultura. Esta política toledana tuvo profundas repercusiones en los indígenas, pues se alteraron las relaciones de parentesco, los circuitos económicos precedentes y el conjunto de elementos de la vida social y cultural existente, generando conflictos y resistencias entre los indios, dado que los apartaba de sus huacas, ancestros y los alejaba físicamente de sus raíces simbólicas, sin las cuales era imposible concebir la vida. $^{29}$

\section{Interacciones culturales, tensiones y tributos indígenas}

La visita general de 1570 a la antigua provincia inca del Colesuyo (Chirinos y Zegarra, 2013) fue realizada por Juan Maldonado de Buendía, quien encontró 226 pueblos que redujo a 22, estableciendo además 13 doctrinas para la administración de los sacramentos, siendo la primera en crearse Hilabaya y luego San Jerónimo de Poconchile (Hidalgo y Focacci, 1986; Hidalgo, 2004; Muńoz y Choque, 2013). ${ }^{30}$ El producto del sistema de reducciones

29 Esta reticencia constante a ocupar los espacios reduccionales se reflejó en la inquietud que causa este hecho en la Iglesia, ya que durante las visitas eclesiásticas dirigidas a los indígenas se indagaba si estos obedecían la prohibición de volver a sus antiguos poblados.

30 Jorge Hidalgo sostiene que con posterioridad al proceso toledano, los pueblos andinos, organizados en el esquema hispano, continuaron desplazándose o cambiando sus asentamientos por diversas causas internas y externas. 
Tabla 2. Indios tributarios declarados en Visita General de Toledo (1570).

\begin{tabular}{|l|c|c|c|c|c|}
\hline & Tributarios & Viejos & Menores -17 & Mujeres & Total \\
\hline Tarapacá, Pica y Loa & 921 & 251 & 1.160 & 2.237 & 4.569 \\
\hline Lluta y Arica & 186 & 54 & 166 & 379 & 785 \\
\hline Ylo e Yte & 50 & 18 & 208 & 109 & 385 \\
\hline Tacna & 660 & 134 & 683 & 1.372 & 2.849 \\
\hline Hilabaya & 299 & 72 & 342 & 755 & 1.468 \\
\hline Total & 2.116 & 529 & 2.559 & 4.852 & 10.056 \\
\hline
\end{tabular}

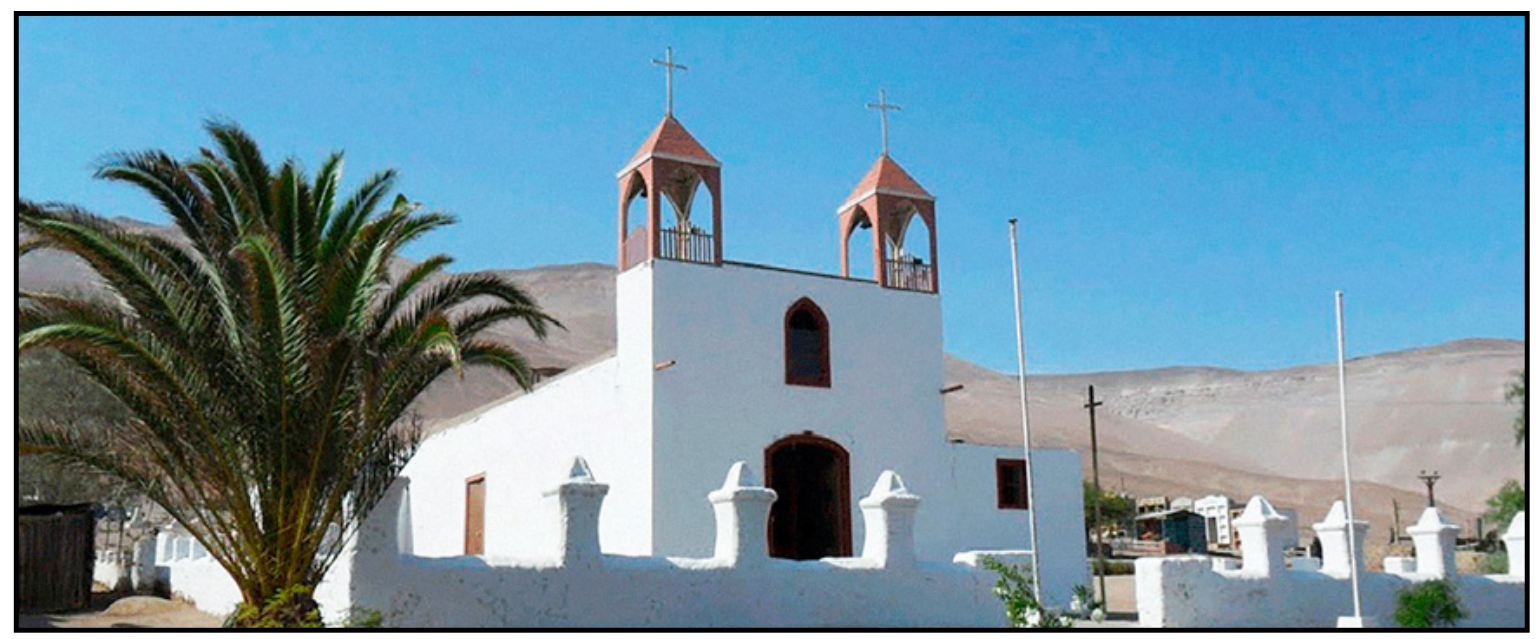

Figura 5. Iglesia de San Jerónimo de Poconchile, valle de Lluta.

fue la construcción ideológica del "indio", sin tener en consideración el mosaico étnico existente. Maldonado de Buendía no vislumbró las profundas diferencias culturales y políticas que existían en esos grupos humanos tan heterogéneos (Murra, 2002; Gareis, 2008). En virtud de ello, los antecedentes demográficos registrados en la visita establecen la existencia de una población total de 10.056 personas, incluyendo a los indios de Tarapacá, Pica y Loa (Tabla 2). ${ }^{31}$ Apartando los indios de Tarapacá, se establece una población tributaria de 1.195 , el 55\% de ella proveniente de Tacna; $25 \%$ de Hilabaya; $16 \%$ de Lluta y Arica; y finalmente el $4 \%$ de Ilo e Ite (Figura 5).

31 Antecedentes obtenidos de la Tasa de la Visita General de Francisco de Toledo, editada por Noble David Cook (1975), pp. xxvii-xliii.
La carga tributaria impuesta a los indios del Corregimiento de Arica alcanzó la suma de 10.841 pesos de ocho. La Data General fue de 4.153 y el saldo de los tributos llegó a la cifra de 6.688 pesos (Figura 6). Un análisis de la Data General da cuenta de un 56,6\% al ramo de Doctrinas; $32 \%$ de Justicia y $11,4 \%$ destinado a los salarios de los caciques. Infortunadamente, la visita general no dio cuenta de las especificidades étnicas de cada repartimiento de Arica como sí lo hizo en Chucuito, Porco y Potosí.

La paulatina contracción demográfica, la presión de los hacendados por tierras en los valles y las demandas de los seńores étnicos carangas liderados por Martin Chuquichambi, ${ }^{32}$ quien requiere la

32 AGI, Justicia, No 658, N² 2, "El fiscal contra Antonio Álvarez, vecino de la Ciudad de la Plata sobre el derecho a la encomienda de Guachacalla. Transacion de Ysasaga con Mendieta”, fs. 673v-674r. 


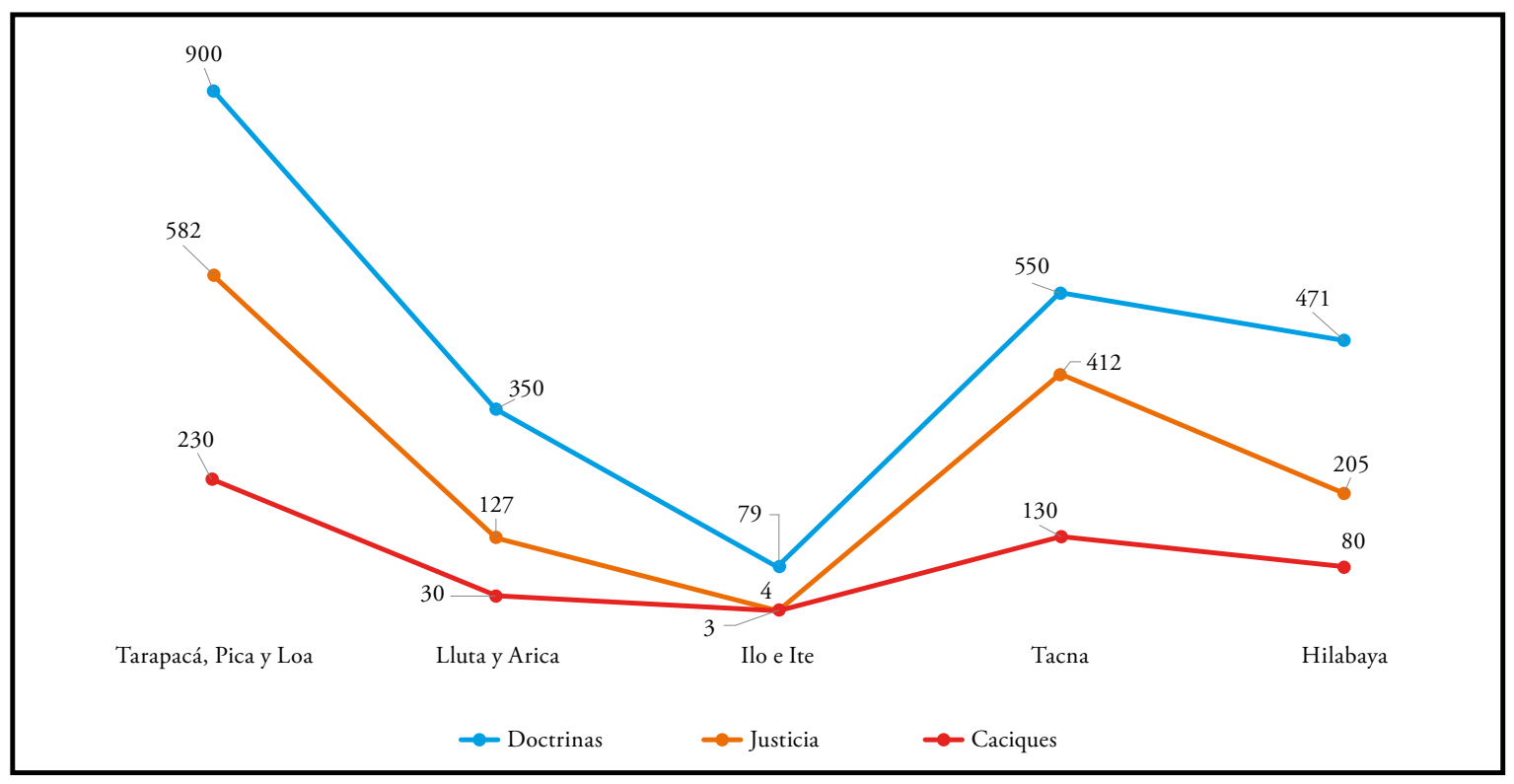

Figura 6. Data General de los repartimientos del Corregimiento de Arica (1570).

devolución de sus antiguos mittanis asentados en los valles de Arica, ${ }^{33}$ contribuyó a los cambios demográficos del territorio y generó posteriores tensiones sociales y culturales.

La creación de las reducciones forjó una base de poder y legitimidad indígena que permitió a los señores étnicos locales el restablecimiento de las viejas prácticas de reciprocidad asimétrica a una escala local, uniendo a poblaciones yungas y mittanis altiplánicos. Al respecto, Ariel Morrone (2017) agrega que la nueva estructura de gobierno toledana generó actores políticos, que desarrollaron diversas estrategias de acumulación de capital para consolidar sus linajes y conservación del poder local en sus unidades familiares. Así, los indios principales de Arica en 1581 unificaron los cacicazgos de Auzipar, Lluta, Huanta y Camanchacas, instalando como señor principal a "Juan Tauqui ó Tauquina, que se hacía reconocer

33 Según se desprende de las declaraciones de Juan Polo de Ondegardo (1560), los indios fugados se dirigían preferentemente a la jurisdicción del Corregimiento de Arica, en la costa, donde habitaban antiguos colonos que no deseaban volver a sus tierras de origen por temor al servicio personal y a los trabajos de mitayos en Potosí. Esta situación permitió que los indios huidos engrosaran el número de tributarios yungas, que estaban exentos de la mit’a de Potosí. como Cacique de Azapa, Chacalluta y Lluta" (Muńoz y Choque, 2013, p. 435). Dicha unión no fue la única, pues a medida que la población se dispersaba o disminuía, nuevamente se reorganizaba el espacio sacralizado y político, permitiendo con ello que los pueblos de Putre, Socoroma, Belén y Codpa gozaran de cierta autonomía económica y política en los siglos venideros (Hidalgo et al., 2004b). La deconstrucción de su organización política creó una redefinición de la territorialidad sagrada, como también una reinterpretación del mundo simbólico, es decir, se forjó una nueva jerarquización de cerros y huacas en el espacio de estudio (Kessel, 2003a; Gil y Fernández, 2008; Sanhueza, 2008b; Choque y Pizarro, 2013), poniendo fin a las relaciones de reciprocidad asimétrica con los señoríos altiplánicos.

Cuatro décadas más tarde, en 1618, el "Carmelita descalzo" Vásquez de Espinoza recorrió el territorio encontrando reducciones afianzadas y según su testimonio, los pueblos están constituidos en su mayoría por un patrón de damero, cuyas calles poseen forma de rejillas ortogonales, y la presencia de un templo cristiano constituye el símbolo más conspicuo de los pueblos de indios (Vásquez de Espinoza, 1948; Durston, 2000). De este modo, el patrón hispano cubrió los Andes con un nuevo orden de cosas, cambiando de modo significativo la forma de vida de las 


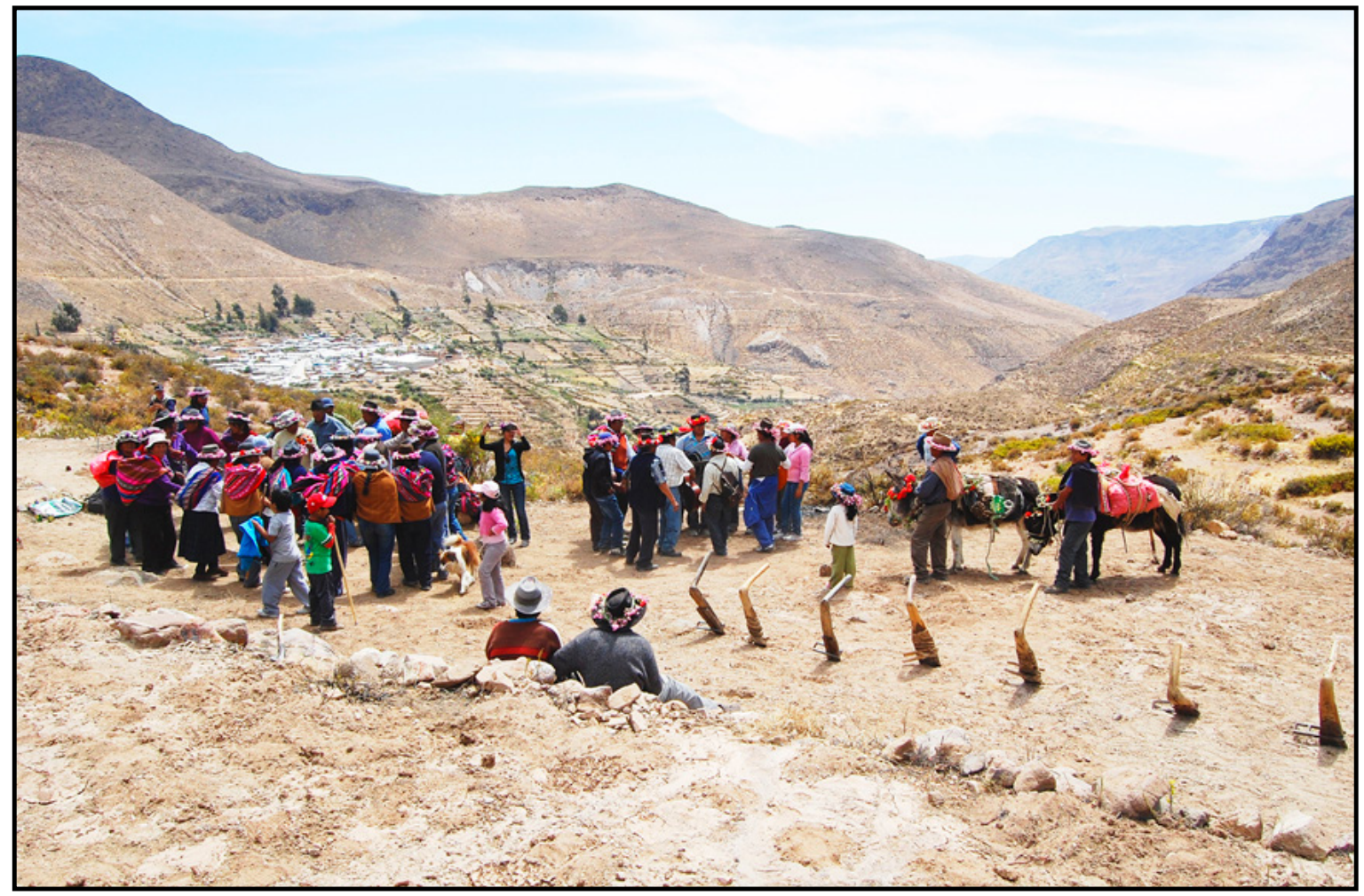

Figura 7. Pueblo de Socoroma en la fiesta del Pachallampe, Altos de Arica.

poblaciones andinas. Si bien la economía agrícola es la misma, se incorporaron al espacio productivo el trigo, la oliva y la vid. No obstante, la conceptualización ideológica del espacio cultural, tecnologías y religiosidad sí cambió significativamente (Marsilli y Cisternas, 2010).

En el aspecto demográfico, fray Vásquez de Espinoza, marginando los datos cuantitativos de Tarapacá y Pica, establece que hay 806 indios tributarios y una población total de 3.018 individuos, es decir, menos un $32,6 \%$ de contribuyentes en comparación a los antecedentes de la visita general del virrey Toledo. Un cotejo de ambos datos censales advierte una contracción de un $45 \%$ en el total de la población indígena de Arica a Hilabaya, pues su disminución fue de 2.469 personas (Figura 7).

El establecimiento de nuevas jurisdicciones administrativas en el espacio andino durante el siglo $\mathrm{XVI}$ generó diversos pleitos entre las autoridades españolas e indígenas en las unidades territoriales recién creadas, y en algunos casos los conflictos se prolongaron a los siglos subsiguientes. Dichos litigios se produjeron por los linderos de repartimientos y cacicazgos, así como también por el control de los indios forasteros de estas jurisdicciones. Los reclamos de los señores principales de Chucuito y Hatun Caranga por sus tributarios y mittanis asentados en Arica fueron expresión de estas controversias (Trelles, 1991; Hidalgo y Durston, 1998; Muńoz y Choque, 2013). Si bien, en el transcurso del siglo XVII las denuncias carangas se reavivaron y enfrentaron a las autoridades hispanas de Arica y Charcas, a consecuencia del incumplimiento de las ordenanzas emitidas por la ciudad de La Plata en 1583, que demandaron al corregidor de Arica la devolución de los indios huidos, "bajo pena que se podrá castigar aunque no sea de ese distrito". ${ }^{34}$ No obstante, dicha ordenanza fue desoída por los oficiales reales de la plaza. El conflicto de los señores principales de Carangas y el corregidor ariqueño en

34 AGI, Charcas 415, L.2, "Real Cédula al presidente y oidores de la Audiencia Real que reside en la ciudad de la Plata, de la provincia de los Charcas, 1592”, fs. 92r-95r. 
1612 radica en la solicitud de dichos indios al virrey del Perú, Juan de Mendoza y Luna, tercer marqués de Montesclaros, la devolución de los carangas que estaban en los altos y valles de Arica. Los reclamos se expresaron en dos cartas enviadas al virrey; la primera solicita justicia a la máxima autoridad colonial, ${ }^{35}$ y en la segunda misiva, rubricada por el presbítero Fernando de Altamirano, suplican la devolución de los indios "huidos". ${ }^{36}$ Además, su-

35 AGI, Charcas 49, L.1, Carta N 1, "Cartas de Turco", f. 1r-1v. "Señor los caciques i principales del Repartimiento de atún Carangas de la Provincia de Carangas suplicamos humildemente a Vuestra Majestad sea servido de pasar los ojos por un memorial que con esta enbia el Licenciado Don Fernando Altamirano, señor cura firmado de nuestros nombres a quien emos pedido que doliéndose de tantos travajos como tenemos de aviso a Vuesta Majestad para que nos haga mersed en lo que en el pedimos es justicia y se conduela vuestra majestad de nuestras dolencias con que las mitas de Potosí y otras muchas obligaciones a que acudimos son tantas, que nos an de acabar no lo mandando vuestra majestad remediar a quien pedimos esto por amor de dios el qual guarde la real persona de Vuestra Majestad y en esta dos acreciente como sus vasallos que nos menester. Et. Don Andres Chuquichambi, Don Juan Condorvilca, Don Juan Palla, Don Fernando Ciques (¿Lipez?), Don Diego Vilca, Don Lázaro Mollo, Don Andres Calisaya, Don Diego Quiqaña, Don Carlos Gutiérrez y Don Javier Coaquira".

36 AGI, Charcas 49, L.1, Carta No 2, "Cartas de Turco", fs. 2r-2v. "Señor Al servicio de dios nuestro señor i de Vuestra majestad i la suma pobreza de muchos trabajos $i$ aberraciones que estos miserables indios padecian i el poco remedio que para ellos tienen sino es que tengo por mano de Vuestra Magestad me an movido a dar cuenta de las cosas acontecidas en el memorial que va con esta i tambien por misericordia rrogando ellos con mucha instancia como a cura suio que soi a quien por la obligación $\mathrm{i}$ amor que les tengo busco ver algo alibiados de travaxos que lo estavan, con la mersed que piden i esperan recurrir de Vuestra Majestad a cuia hacienda tambien se les sigue algun aumento en que estos indios permanescan en las mitas de Potosí de todo podra informar el licenciado Alonso de Maldonado, presidente que fue en Vuestra Real Audiencia de los Charcas i yo mandandomelo a Vuestra Majestad acuidire también a cuidar en esta reducción como persona que conose la gente save las partes donde estan huidos i que desto tenga efecto y lo principal por lo que toca al descargo de la conciencia de Vuestra Majestad cuia vida conserve. Reciba muchos años i en estados de creciente Hacienda. Fecha en este pueblo de Hatun Carangas a primero de henero de 1612 años. Licenciado Don Fernando Altamirano". man al escrito un memorial donde piden que los indios reducidos en Tocoroma (hoy Belén) vuelvan a la jurisdicción de Turco y cumplan las obligaciones tributarias y mitas que tienen los demás indios carangas. ${ }^{37}$ Bajo el reinado de Felipe III, en 1618 se instruyó que ningún indio de un pueblo se vaya a otro, bajo pena de azotes y multas, prohibiéndose además el otorgamiento de licencias para salir de las reducciones. ${ }^{38} \mathrm{~A}$ pesar de ello, las autoridades locales, indios principales y los propios indios huidos o forasteros en la jurisdicción ignoraron tales requerimientos de las autoridades de Charcas y las emitidas por la Corona.

37 AGI, Charcas 49, L.1, "Memorial de los Caciques de Hatun Carangas", fs. 3r-4r. "Los caciques i principales del repartimiento de Hatun Carangas suplican a Vuestra Majestad: Que Vuestra Majestad mande que los indios del dicho corregimiento de provincia de Carangas que desde antes de la vida que hizo don Francisco de Toledo, vuestro visorrei estan en los altos i balles de Arica, se rreduzgan al pueblo de Tocoroma questa en los mismos altos donde tienen tierras en que sembras el qual esta sujeto al corregidor desta dicha provincia de carangas i a los caciques del pueblo de turco i de allí acudan a la mita de Potosí, trajin de barras i azogues i demas obligaciones que tienen los dichos indios carangas, sin que los corregidores de Arica tengan jurisdiçion ni dominio sobre ellos, por cuia causa i con cuio fabor estan lacándos un menos a su corregidor, ni caciques ni pagan tasa ni sirven mitas del cerro ni ingenios de Potosí las quales cumplen sus caciques a costa de los demas indios pagando por cada uno de los fugitivos setenta y dos reales cada semana que es cosa lastimosa por la qual an bendido sus ganadillos ibertidos i algunos se de cierto que hasta las propias mujeres i hijos tienen empeñados y no asi quien se duela ni trate de rremediárlo. Que Vuestra Majestad asimismo mande que los indios que desde la dicha misma fecha a esta parte tambien sean huido $i$ ausentado de sus pueblos a los dichos altos de Arica i otras partes se buelban a rreducir aellos con sus familias y ganados i que si se bolviesen a huir como cada día lo haben sean con todo rigor exemplarmente castigados por ser esta gente detal inclinación que sin el no haber cosa ni los que pueden i a sujetar. Los caciques ni las justicias que no mandandolo Vuestra Majestad en breve tiempo se abandonan y desolan los pueblos de que a Vuestra Real Hacienda sele seguira disminución por estar conjuntos a Potosí [...]".

38 Recopilación de Leyes de los Reynos de las Indias, Libro VI, Título III, Ley XVIII; p. 230, "Que ningún indio de un pueblo se vaya a otro" y Ley XIX, p. 230 "Que no se de licencia a los indios para vivir fuera de sus reducciones". 
La contracción demográfica de los indios originarios del territorio obligó a tolerar la presencia forastera y a omitir los instructivos judiciales, dada su importancia para la economía local. Las prohibiciones de aceptar o tolerar indios forasteros se incluyeron en los documentos civiles y eclesiásticos. Estos últimos exigen, por ejemplo, que se registre tras previa autorización todo matrimonio entre indios originarios y forasteros. ${ }^{39}$ Del mismo modo, en 1634 se indicó a los curas de la Diócesis de la Paz que "no se admitan en sus haciendas y servicios a indios forasteros". ${ }^{40}$ Sin embargo, en ocasiones fueron los mismos doctrineros quienes requirieron de forasteros que supiesen leer y escribir o dominaran el latín y lenguas nativas para profundizar la evangelización de la población indígena local, como se evidenció en el pueblo de Socoroma, donde colaboraba con la doctrina un indio forastero..$^{41}$ Este tipo de hechos fue considerado por la Audiencia de Charcas como el propiciador de los desórdenes introducidos por los curas doctrineros, que fomentaron la existencia de indios huidos de las obligaciones tributarias y mitas a excusa de servir en la Doctrina. ${ }^{42}$ A fines del siglo XVII la generalización de las huidas obligó al virrey Melchor de Liñán y Cisneros, arzobispo de Lima entre 1678 a 1681, a instruir el cobro de sínodos y tributos a los indios forasteros del Virreinato del Perú y Audiencia de Charcas, reafirmando así su contribución a la Real Hacienda, ${ }^{43}$ pues en

39 Archivo Arzobispal de Arequipa (en adelante AAA), Serie Arica, Legajo 12, "Visita Eclesiástica del Licenciado Juan Guerrero de Vargas, cura y vicario de Arica, 1632 ", f. 8v. "Y si ssaven a administrado el sacramento del matrimonio conforme a derecho dexando en su libertad alos contraientes y (hoja deteriorada) Advierto algunos impedimentos o difísil el haceso o si a Cassado algunos forasteros sin lizencia del prellado al Que aya precedido ynformacion de su libertad".

40 AGI, Charcas 415, L.3, "Real Cédula al obispo de la iglesia catedral de la ciudad de La Paz, de las provincias del Perú, del Consejo Real”, fs. 216r-216v.

41 AAA, Serie Arica, Legajo 12, "Visita Eclesiástica del Licenciado Juan Guerrero de Vargas...”, op. cit., f. 23 r.

42 AGI, Charcas 415, L.3, "Real Cédula al obispo de la iglesia catedral de la ciudad de La Paz, de las provincias del Perú, 1637”, fs 248v-249v.

43 AGI, Charcas, 416, L.6, "Real Cédula al padre don Melchor de Liñán y Cisneros, arzobispo de la iglesia metropolitana de la ciudad de Los Reyes, en las provincias del Perú, del Consejo del rey, virrey, gobernador y capitán general de ellas en ínterin, 1680”, fs. 259r-259v.
1628 el rey Felipe $I^{44}$ ya había instruido que se cobrasen las tasas a los indios que estaban fuera de las reducciones. ${ }^{45}$ En otros casos, los indios foráneos simplemente fueron convertidos administrativamente en originarios, tal como acaeció en $\mathrm{La} \mathrm{Paz}$ en 1792 (Saignes, 1985). Sin embargo, la medida demandó la aplicación de prerrogativas y derechos sobre la tierra de parte de los nuevos originarios. Una situación análoga se expresó en Cajamarca, ya que los indios recategorizados exigieron el acceso a la tierra para dejar la condición de forastero (AlbiezWieck, 2017).

En consecuencia, durante el siglo XVII e inicios del XVIII, las poblaciones indígenas desde Quito a Buenos Aires privilegiaron huir hacia territorios marginados de la mita potosina o hacia los centros urbanos o mineros y vender ahí su fuerza laboral, desarraigándose de sus comunidades de origen. Situación que será advertida por las autoridades hispanas que instruyen el empadronamiento o registro de los indios naturales y forasteros, dada la "continua reducción de los mitayos que llegaban a Potosí" (Castro y Palomeque, 2016, p. 46). No obstante, las autoridades de Arica, Chuquisaca y Oruro no remitieron el informe solicitado por las autoridades de Potosí, pues en algunos casos los huidos y forasteros trabajaban en las haciendas de connotados vecinos de Arica o Tacna. La expulsión de dichos indios advenedizos hubiese significado un grave perjuicio a las economías locales como también al Patrimonio Regio del corregimiento. Al mismo tiempo, realizar un registro y matrícula de esta población era una empresa compleja y costosa por el alto grado de movilidad y ausentismo de los indios.

44 Recopilación de Leyes de los Reynos de las Indias, Libro VI, título V, Ley VI, página 240, "Que se cobre la tasa de los indios que estuvieren fuera de sus reducciones".

45 En el Virreinato de la Plata en 1792 se dictaron disposiciones oficiales tendientes a fijar residencia y tributación definitiva en otras jurisdicciones, de aquellos originarios de otros repartimientos. 


\section{Epidemias, revisitas y filiaciones de indios forasteros en los Altos de Arica y Tacna entre 1680 y 1793}

La primera mitad del siglo XVIII estuvo marcada por una serie de desastres naturales y enfermedades que asolaron los territorios indianos, generando una contracción demográfica de un cuarto de la población (Walker, 2003). Las epidemias que afectaron al Virreinato del Perú y Audiencia de Charcas entre 1717 a 1720 fueron devastadoras para la sociedad y economía colonial, llegando a abatir significativamente los ingresos de la Real Hacienda (Pearce, 2001; Huerta, 2009; Carcelén, 2011). La última gran peste se desató en el puerto de Buenos Aires, ${ }^{46}$ propagándose luego hacia Charcas y finalmente al sur del Virreinato del Perú, conmoviendo de manera dramática las provincias de "Cusco", "Huamanga" y "Arequipa" (Laviana, 1983, p. 656; Contreras, 2001, p. 89). El historiador tacneño Luis Cavagnaro sugiere que el barco infestado pudo ser el "León Franco", que recaló en "Arica" (Cavagnaro, 2005, p. 159). La peste proveniente de este puerto o Buenos Aires tuvo sus mayores efectos en julio de 1718 y 1719, generando un aumento sustancial de muertes entre los indios, cuyos decesos alcanzaron un promedio de 9,19 fallecidos por mes en el corregimiento. En las décadas siguientes, los rebrotes epidémicos afectarán el territorio, pero con una menor tasa de mortalidad en españoles y demás castas.

La continua presión hacendística de las autoridades de Charcas llevó a los señores principales carangas a renovar sus esfuerzos por la recuperación de indios huidos y antiguos colonos ubicados en los Altos de Arica (Saignes, 1991) y así cumplir con sus obligaciones tributarias y mitas a Potosí. Al respecto, Jorge Hidalgo y Alan Durston exponen que los oficiales de Arica, desde el siglo XVII, aplicaban una ordenanza de naturalización para indios forasteros que habitasen el territorio por "más de cincuenta años" (Hidalgo, 2004, p. 516). ${ }^{47}$ Sin embargo, estas disposiciones no evitaron que el Corregidor de Pacajes

46 La epidemia no ha sido bien identificada, pero se cree que fue cólera, tifus o peste bubónica.

47 Ambos autores sostienen que dicha ley de los diez años facilitó considerablemente la incorporación de forasteros en el Corregimiento de Arica. se llevase compulsivamente a unos 120 indios forasteros agregados en 1661. El efecto de la medida acrecentó la pérdida del control que ejercían los pacajes y carangas sobre sus antiguos mittanis y los espacios productivos costeros, cuyo vacío de poder fue ocupado por el Cacicazgo de Codpa (Cuneo-Vidal, 1977a; Hidalgo, 2004). Igualmente, los caciques tendían a promover la asimilación y asentamiento de indios forasteros en tierras comunales para incrementar la mano de obra necesaria para afrontar las obligaciones tributarias (Serulnikov, 2003). Más tarde, las nuevas ordenanzas reales vinieron a consolidar la naturalización y la presencia de los forasteros, ya que una vez registrados, debían pagar un tributo específico en los territorios donde residían, aunque menor en cuantía en relación a la contribución de los originarios (Gavira, 2008).

Los conflictos por los indios forasteros de Arica se reinició unos 10 años antes de la peste, puesto que en 1710 , los carangas se quejaron contra el cacique de Codpa, don José Cañipa, por ocupar unas chacras en Azapa donde se introdujo con "mano fuerte en las tierras de las comunidades de Turco" (Cuneo-Vidal, 1977a, p. 375). Si bien los tribunales limeños respaldaron las peticiones carangas contra Cañipa, para entonces los reclamantes ya no podían ejercer un dominio efectivo sobre el territorio. A la muerte de don José, le sucedió su hijo Ignacio Cañipa ${ }^{48}$ quien acabó finalmente con la autoridad política de los Carangas "dentro de este repartimiento de los Altos de Arica, y los colonos carangas fueron integrados al cacicazgo de Codpa" (Gavira, 2008, p. 22). Dicho triunfo se debió fundamentalmente al apoyo obtenido de las autoridades del corregimiento y la reticencia de los antiguos colonos a tener dependencia de los indios principales de Turco.

A mediados del siglo XVIII se evidencia una leve recuperación demográfica del Corregimiento de Arica, que fue consignada en las revisitas de 1750 y 1772 (Hidalgo, 1978; Hidalgo et al., 2004b), y luego en la

48 Ignacio Cañipa contrajo nupcias con la hija del cacique de Tarata, don Roque Ticona, consolidando de esta manera el sistema de alianzas matrimoniales de los caciques locales y profundizando el poder local en el Corregimiento de Arica. En la misma época Rosa, la segunda hija de don Roque, se casó con el cacique de Tacna, don Pedro Ara. 
Tabla 3. Indios tributarios del Corregimiento de Arica en 1753.

\begin{tabular}{|c|c|}
\hline Repartimiento & Indios tributarios \\
\hline Tarapacá & 491 \\
\hline Ilabaya & 177 \\
\hline Tarata & 409 \\
\hline Tacna & 543 \\
\hline Codpa & 631 \\
\hline
\end{tabular}

visita general del Intendente de Arequipa, don Antonio Álvarez y Ximénez en 1793 (Paz Soldán, 1984; Cañedo-Argüelles, 1995; Marchena, 2005; Choque, 2018). La primera revisita aludida fue requerida en 1749 por el virrey del Perú y conde de Superunda, don Juan Antonio Manso de Velasco, quien encargó el empadronamiento de la jurisdicción al corregidor Joseph de Ureta, el cual inició en 1750 recuento solicitando a los sacerdotes la presentación de los libros de bautismo, casamientos y defunciones e instruyó a los caciques del repartimiento la publicación y pregón de los bandos respectivos. Los resultados de la revisita ejecutada por el tesorero don Joaquín de Cárdenas, según Vicente Dagnino ${ }^{49}$ dan cuenta de 2.251 indios tributarios pertenecientes a cinco repartimientos. No obstante, las cifras del repartimiento de Tarapacá consideraron solo a los indios de Pica y Tarapacá, excluyendo antecedentes de los indios de Sibaya y Camiña, que eran parte de dicho territorio (Tabla 3). Así, los reales tributos se consignaron principalmente en los indios de Tacna y Codpa, con un $24 \%$ y $28 \%$ respectivamente (Figura 8 ).

La revisita de Cárdenas informa que la jurisdicción del Cacicazgo de Codpa poseyó un total de 2.758 personas, de los cuales el $21 \%$ eran indios tributarios; $0,5 \%$ forasteros, y $0,1 \%$ ausentes. El análisis de los datos permite identificar que los pueblos de indios con un mayor porcentaje de indios tributarios originarios son Socoroma y Sora respectivamente. Opuestamente, Guallatire y el Ayllu Copanique de Codpa poseyeron un 2,1\% de indios forasteros (Figura 9). Respecto al origen de los indios forasteros reconocidos en los pueblos de Codpa, Belén

49 Dagnino, “Correjimiento de Arica...”, op. cit., pp. 202 203. y Guallatire, estos provienen de los corregimientos de Carangas con $57,5 \%$, Oruro proporciona un $25 \%$, Arica y Paria aportan el 6,75\% y Chucuito con $5 \% .^{50}$

Años más tarde, el nuevo corregidor de Arica, Demetrio Egan, ${ }^{51}$ instruyó la revisita al Corregimiento en 1772 con la finalidad de establecer la nueva carga impositiva a la jurisdicción, pero infortunadamente no hay antecedentes del Cacicazgo de Tacna, por lo que solo se exponen los datos de los cacicazgos de Codpa, Tarata e Hilabaya. La revisita consigna que los tres cacicazgos mencionados poseen una composición demográfica y tributaria disímil, identificándose a 5.981 indígenas de todas las edades, sexo y origen. Un análisis de la población masculina susceptible al pago de los reales tributos permite identificar un $83,7 \%$ de indios tributarios, $11,1 \%$ de forasteros y un $5,2 \%$ corresponde a las castas de mestizos, ya sean cholos o zambaigos (Figura 10)..$^{52}$

En los tres casos, el corregidor Egan exigió que se "manden, y apremien a los casiques a que exhiban el Padrón de la revisita antecedente, y la última retaza", 53 además de los libros de bautismo y defunciones de

50 Archivo Histórico Nacional (en adelante AHN), Administrativo de Arica, Legajo 3, "Revisita a los Altos de Arica, efectuada por el Oficial Real don Joaquín de Cárdenas, 1750", fs. 1r-88v.

51 Archivo Departamental de Tacna (En adelante ADT), Serie Corregimiento/Subdelegación Gobierno, Legajo 1, "Revisita y numeración de los indios de Codpa, con sus aillos de Copanique, Pachica, Esquiña, Timar, Tignamar, aillo Guallatire, Sacsamar, Pachama, Umagata, Livilcar, Belén, Aillo Mancasaya, Aillo Anansaya, Socoroma, Sora, Putre, Parinacota, Asiento de Choquelimpie, Aillo de Caquena, todos pertenecientes a la Doctrina de Codpa, en los Altos de Arica", fs. 1r-79r.

52 ADT, Serie Corregimiento/Subdelegación Gobierno, Legajo 1 "Revisita y numeración de los indios de Codpa...”, fs. 1r-79r; AHN, Administrativo Arica, Legajo 3, pieza 17, "Visita al pueblo de San Pedro de Hilabaya, jurisdicción de San marcos realizada por el General Don Demetrio Egan de la Orden de Santiago, Theniente Coronel delos Reales Exercitos, Correxidor y Justicia maior, 1772", fs. 1r-52v; AHN, Administrativo Arica, Legajo 4, pieza 34, "Visita al pueblo de San Benito de Tarata realizada por el General Don Demetrio Egan de la Orden de Santiago, Theniente Coronel de los Reales Exercitos, Correxidor y Justicia maior, 1773", fs. 1r-81v.

53 AHN, Administrativo Arica, Legajo 3, pieza 17, "Visita al pueblo de San Pedro de Hilabaya...”, op. cit., f. 1v. 


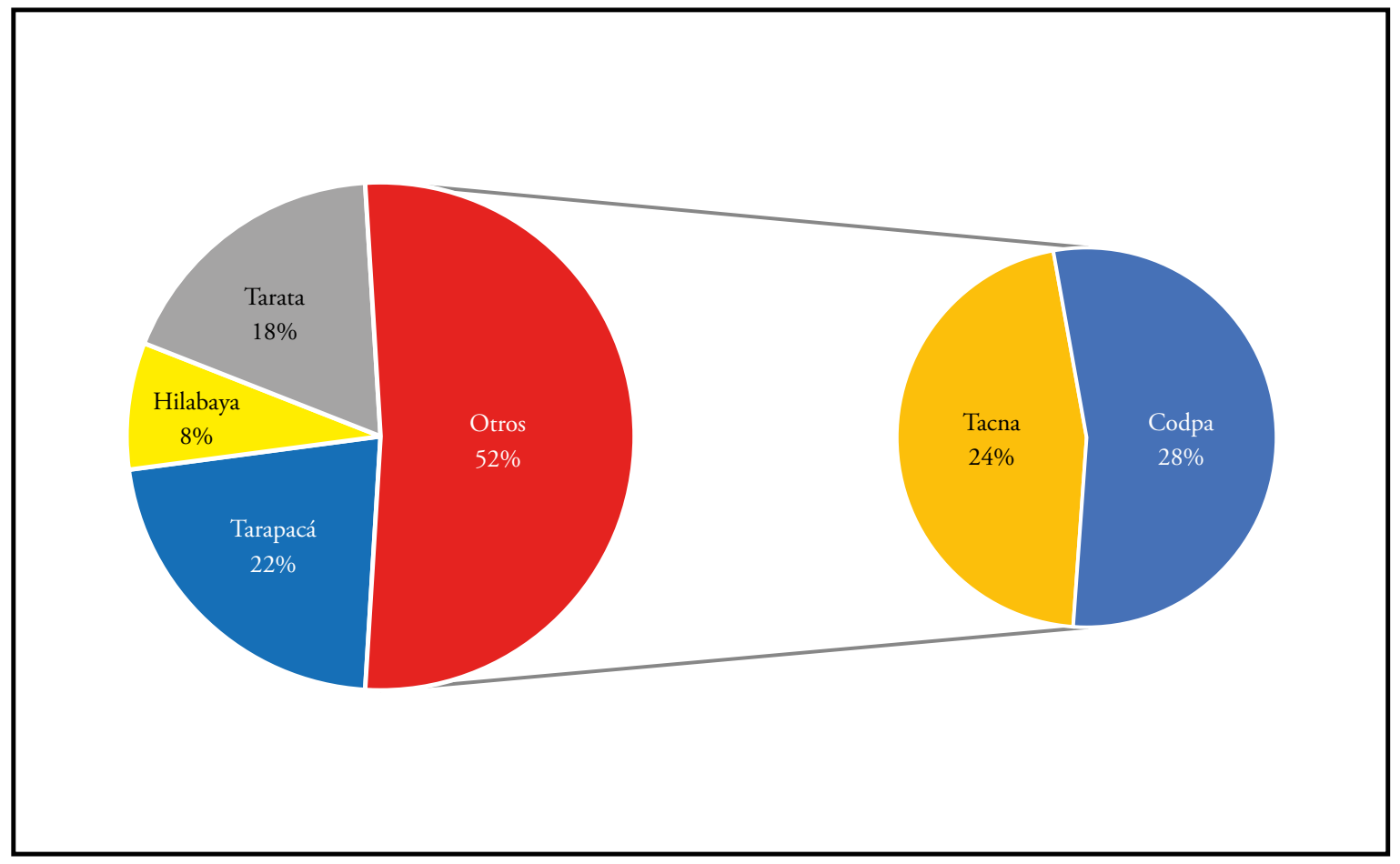

Figura 8. Distribución porcentual de los tributos reales del repartimiento (1750).

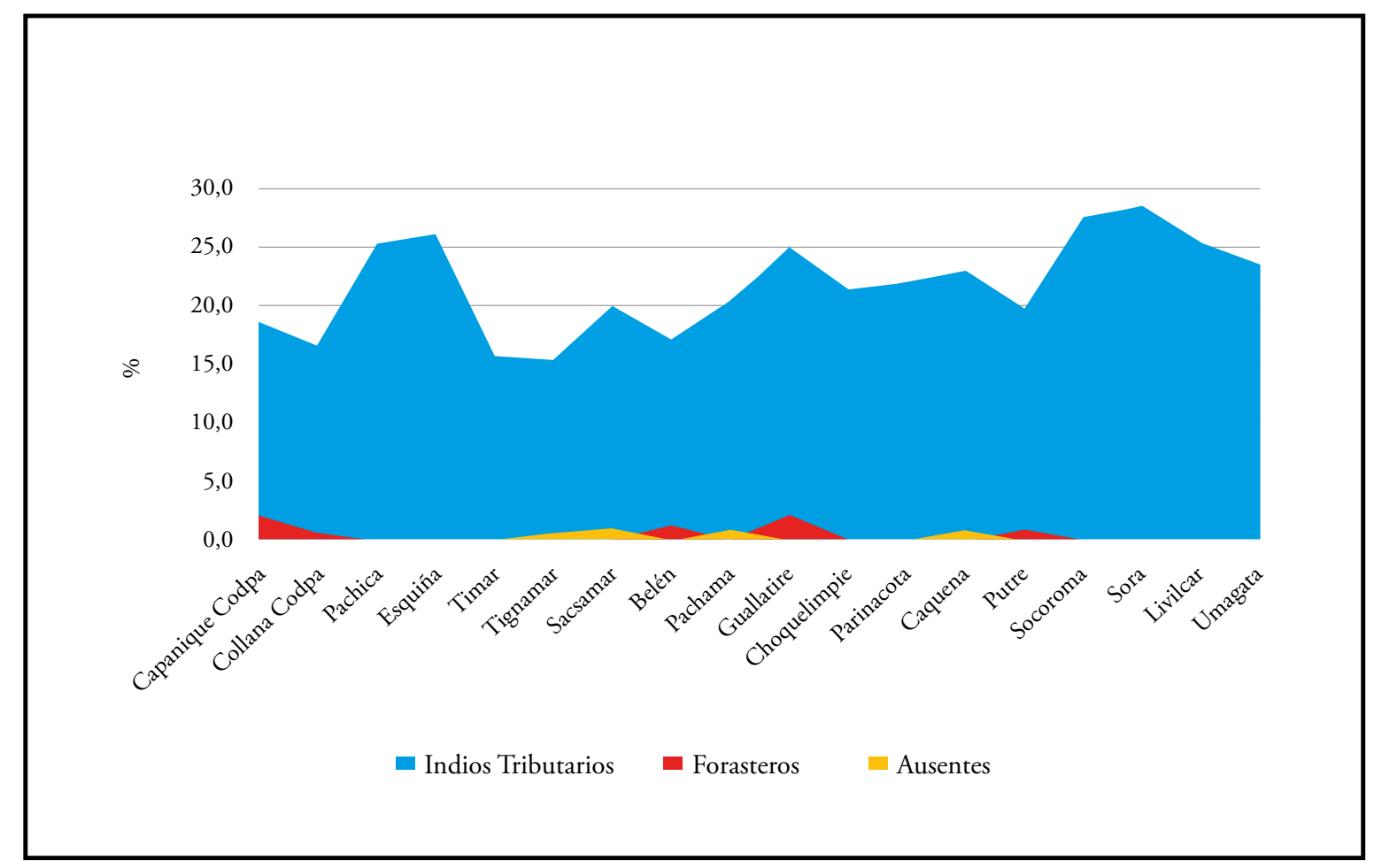

Figura 9. Porcentaje de indios tributarios originarios, forasteros y ausentes del Cacicazgo de Codpa en relación a su población total en 1750 . 


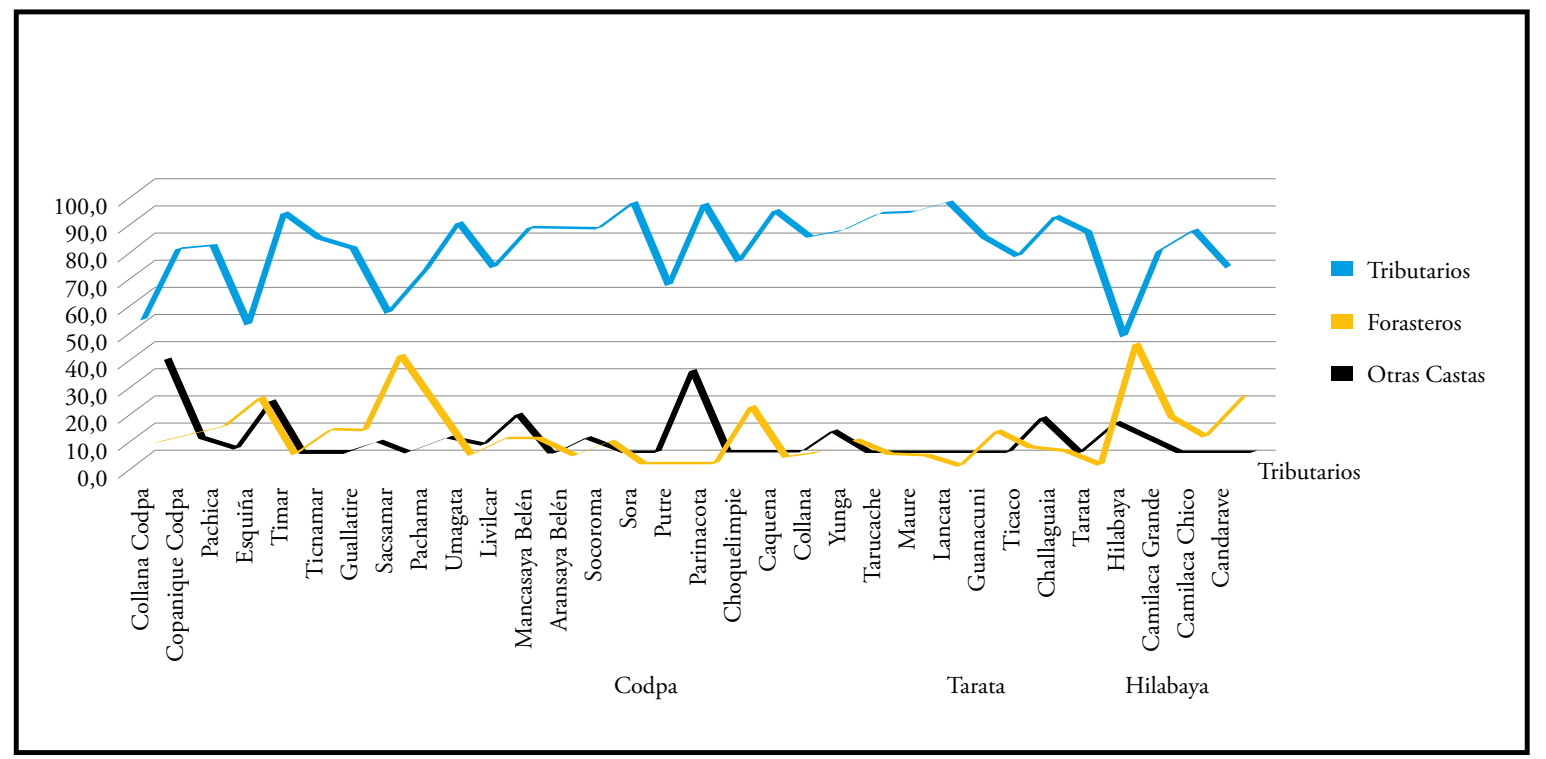

Figura 10. Indios tributarios originarios, forasteros y otras castas de los cacicazgos de Codpa, Tarata e Hilabaya en 1772-1773.

cada anexo. Al respecto Jorge Hidalgo y equipo consideran que las certificaciones de defunciones era motivo de conflicto entre las comunidades y el clero, dado lo oneroso de los documentos (Hidalgo et al., 2004b). El empadronamiento informa la recuperación vegetativa de la población indígena y por ello, el corregidor de Arica buscó incrementar ostensiblemente los ingresos de la Real Hacienda, registrando como tributarios a menores de 18 años e incluyendo también a cholos y zambaigos, "que reclamaban para sí la condición de mestizos" (Hidalgo et al., 2004b, p. 107). Situación que explica el alto porcentaje de población tributaria en Codpa, Hilabaya y Tarata, que se expresó en la recaudación de 11.191 pesos en 1774 y que ascendió a 29.442 pesos en $1779 .{ }^{54}$ En este sentido, el impacto de la política fiscal de Egan logró aumentar la rentabilidad del "espacio regional" (Araya, 2003, p. 144), generando con ello el descontento de la población indígena en los años previos a la gran rebelión andina de 1780 .

La identificación de los forasteros asentados en el corregimiento es heterogénea, pues en cada cacicazgo se presentan singularidades y especificidades (Tabla 4).

54 Biblioteca de Derecho de la Universidad de Chile (BDUChile), Colección Histórica, "Caxas Reales de Arica, 1759 - 1777".
Tabla 4. Porcentajes de forasteros por corregimiento de origen en Codpa, Tarata e Hilabaya en 1772-1773.

\begin{tabular}{|l|c|c|c|}
\hline Corregimientos & Codpa & Tarata & Hilabaya \\
\hline Arica & 13,3 & 5 & 14,6 \\
\hline Moquegua & 2,4 & - & 6,7 \\
\hline $\begin{array}{l}\text { Characato y } \\
\text { Vitor }\end{array}$ & 1,1 & - & 3,4 \\
\hline Abancay & 1,1 & - & 1,1 \\
\hline Vilcabamba & - & - & 1,1 \\
\hline Quispicanchis & - & - & 1,1 \\
\hline Azangaro & - & - & 1,1 \\
\hline Paucarcolla & 1,1 & - & 1,1 \\
\hline Chucuito & - & 77,5 & 55,2 \\
\hline Pacajes & 4,4 & 15 & 7,9 \\
\hline La Paz & 4,4 & 2,5 & 3,4 \\
\hline Omasuyos & - & - & 2,2 \\
\hline Carangas & 62,2 & - & - \\
\hline Paria & 1,1 & - & - \\
\hline Oruro & 2,2 & - & - \\
\hline La Plata & - & $-1,1$ \\
\hline Desconocido & 6,7 & - & - \\
\hline
\end{tabular}




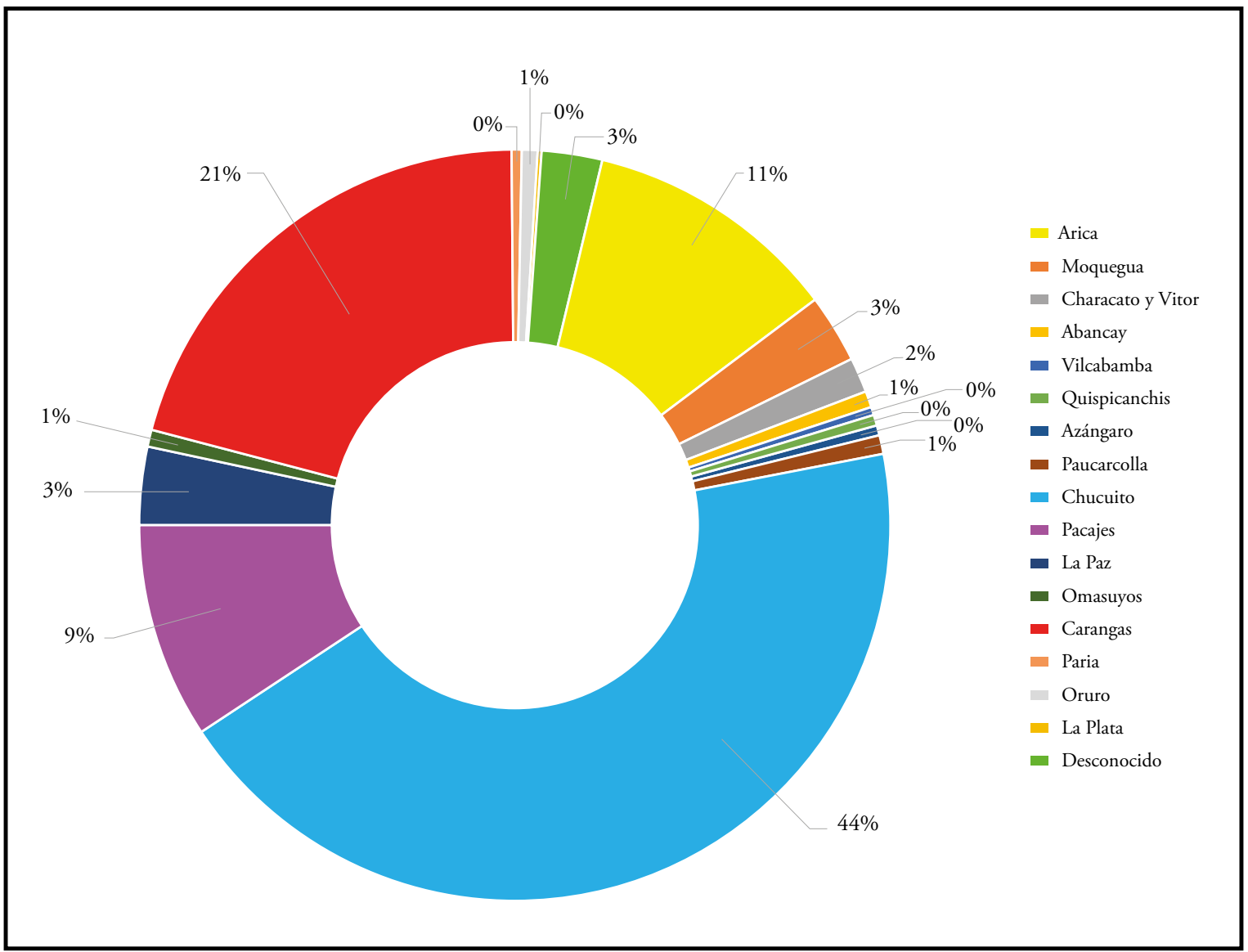

Figura 11. Distribución global de indios forasteros en el Corregimiento de Arica según revisita de Demetrio Egan, 1772-1773.

Un desglose de los datos revela la influencia demográfica de indios provenientes de los corregimientos de Chucuito, Carangas, Pacajes y Moquegua, como también una feble presencia de indígenas foráneos en el Cacicazgo de Tarata. No deja de ser reveladora la inmigración interna en el corregimiento, la que alcanza un promedio de $11 \%$. Cifra igualmente importante es el $2,6 \%$ de forasteros de origen desconocido que se encontraban asentados en el espacio regional (Figura 11).

Respecto al Cacicazgo de Codpa, que ha sido definido como una "construcción colonial" (Hidalgo et. al., 2004b, p. 103), los antecedentes expuestos por Egan informan que el territorio posee un $82,2 \%$, de indios originarios y solo un $11 \%$ de migrantes, situación que implica la rápida naturalización de los forasteros, dado el incremento de tributarios en los registros eclesiásticos y civiles de la época. Un cotejo del origen de forasteros permite identificar un 65,5\% de indios provenientes del antiguo espacio caranga, un $8,8 \%$ de la órbita pacaje y un $1,2 \%$ de la zona lupaca. Sobre la base de 19 pueblos y ayllus del cacicazgo, se observa una presencia caranga en Esquiña (30,4\%), Pachica (10,7\%), Pachama $(8,9 \%)$ y Ayllu Mancasaya de Belén y Sacsamar (7,1\%). El 35,8\% restante de los forasteros carangas se distribuyó en los demás pueblos de indios (Figuras 12 y 13). Por otra parte, la presencia pacaje se localizó principalmente en Socoroma (25\%) y el resto en Collana Codpa, Guallatire, Pachama, Livilcar, Ayllus Mancasaya y Aransaya de Belén.

Si bien la presencia caranga en Arica ha sido evidenciada tempranamente en el siglo XVI por Gilles Rivière, Jorge Hidalgo y Guillermo Focacci, cabe la siguiente interrogante: ¿Existió continuidad demográfica y cultural caranga en el territorio de estudio? 


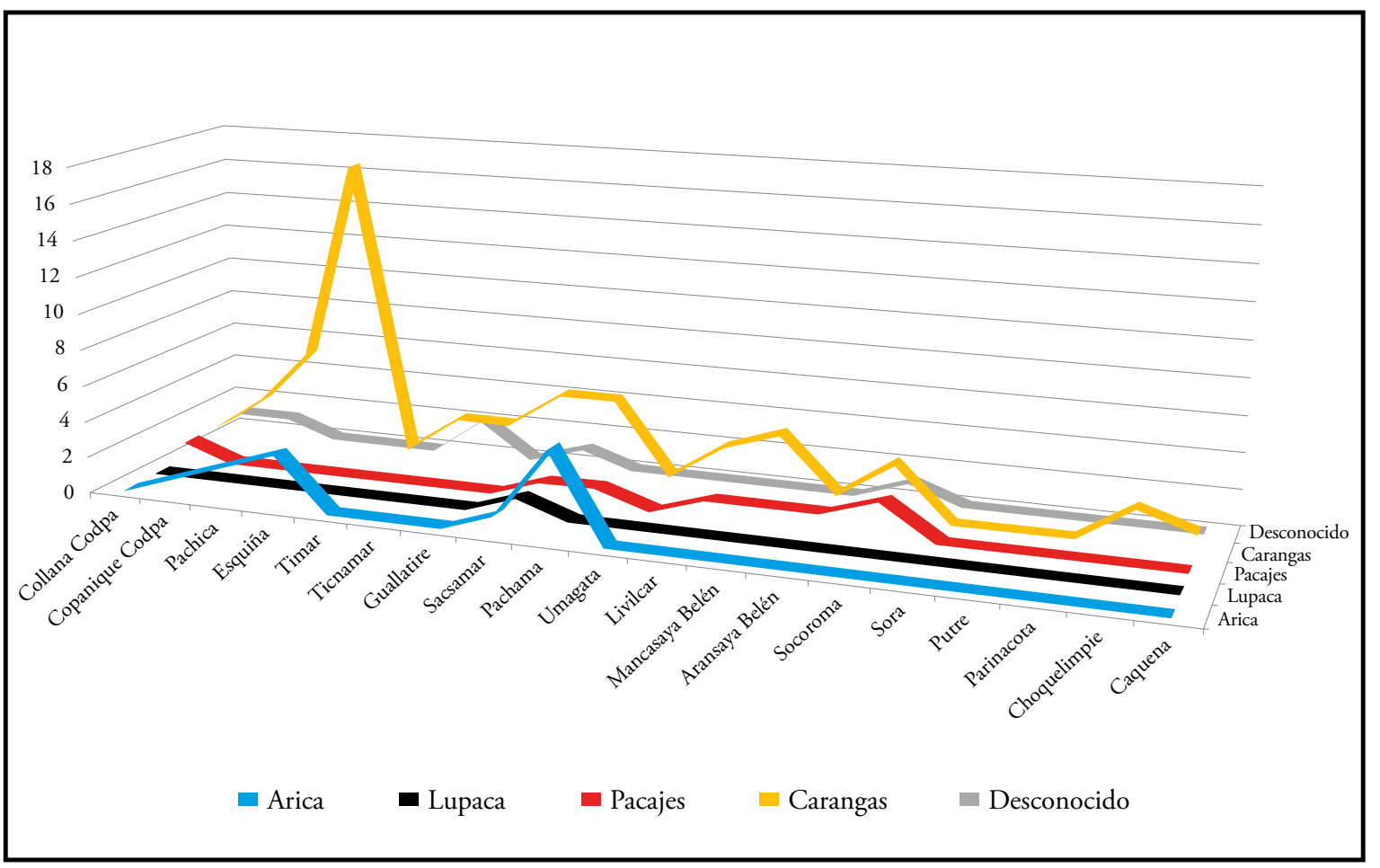

Figura 12. Presencia de indios forasteros en el Cacicazgo de Codpa en 1772-1773.



Figura 13. Distribución porcentual de forasteros en los cacicazgos del Corregimiento de Arica según Demetrio Egan, 1772-1773. 


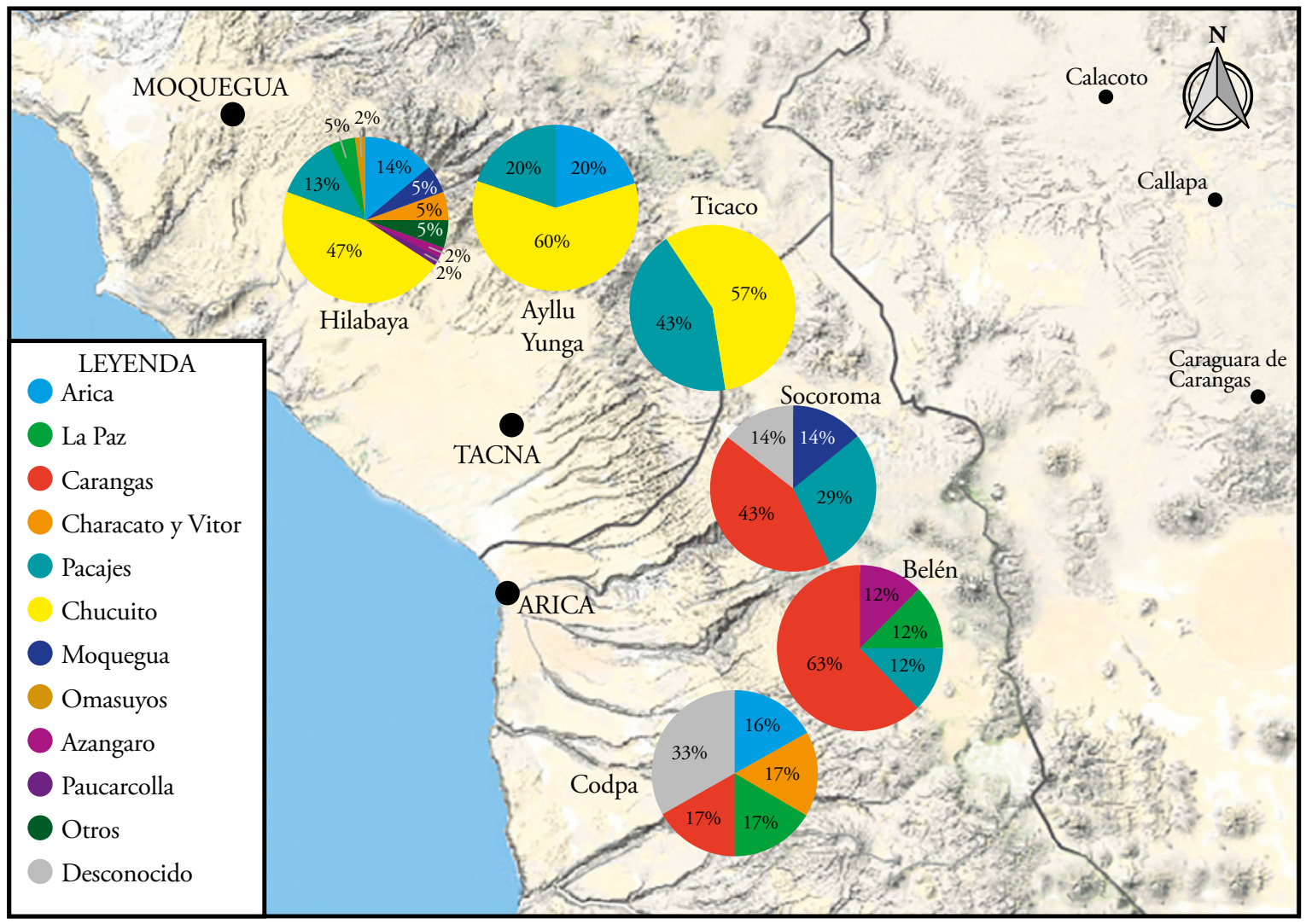

Figura 14. Presencia de indios forasteros de otros corregimientos en los pueblos de Hilabaya, Ayllu Yunga, Ticaco, Socoroma, Belén y Codpa del Corregimiento de Arica según revisita de Demetrio Egan, 1772-1773.

Dicha interpelación surge debido a los datos expuestos por Rivière quien, acudiendo a la revisita del duque de La Palata en 1683, expone que los carangas ausentes, que están en Arica, eran solo 6, versus los 243 indios que estaban en Cochabamba, ello considerando que había un total de 814 ausentes (Rivière, 1982, p. 74). ${ }^{55}$ En otras palabras, el duque de La Palata advierte que el 99\% de los forasteros carangas estaban desperdigados en la Audiencia de Charcas y solo el $1 \%$ en el Corregimiento de Arica. Coincidentemente, Ximena Medinacelli informa que en 1686 el $100 \%$ de indios ausentes de Curaguara de Carangas está residiendo en Potosí, Cochabamba, Paria, Caracollo, Sipe Sipe, Oruro, Omasuyos,

55 Rivière localiza a los ausentes carangas en Tarapacá (2), Lipes (49), Arica (6), Pacajes (28), Carangas (53), Sica Sica (50), Oruro (67), Paria (68), Aullagas (33), Cochabamba (243), Chayanta (35), Ocuri (40), Porco (11), Charcas (17), Potosí (49), Chichas (11), Tomina (4) y Yamparaes (5).
Chayanta y Santa Cruz de la Sierra, entre otros (Medinacelli, 2010, pp. 334-336), no identificándose ningún indio del dicho pueblo en Arica o Tarapacá (Figura 14).

Coincidentemente, el estudio de Raquel Gil Montero, Carolina Rivet y Fernando Longhi (2017) ha propuesto que las provincias que tuvieron la obligación de enviar indios a la mita de Potosí sufrieron un mayor despoblamiento, mientras aquellos territorios no mitayos tuvieron una alta proporción de indios forasteros (Gil Montero et al., 2017). Las regiones "vacías" resultaron ser aquellas designadas en la visita toledana como mitaya, situación que será evidenciada por el virrey Melchor Navarra y Rocafull, duque de La Palata.

Los antecedentes de 1683 y 1772 permiten sugerir que la economía minera influyó en las migraciones de la mano de obra altiplánica, que prefirió 


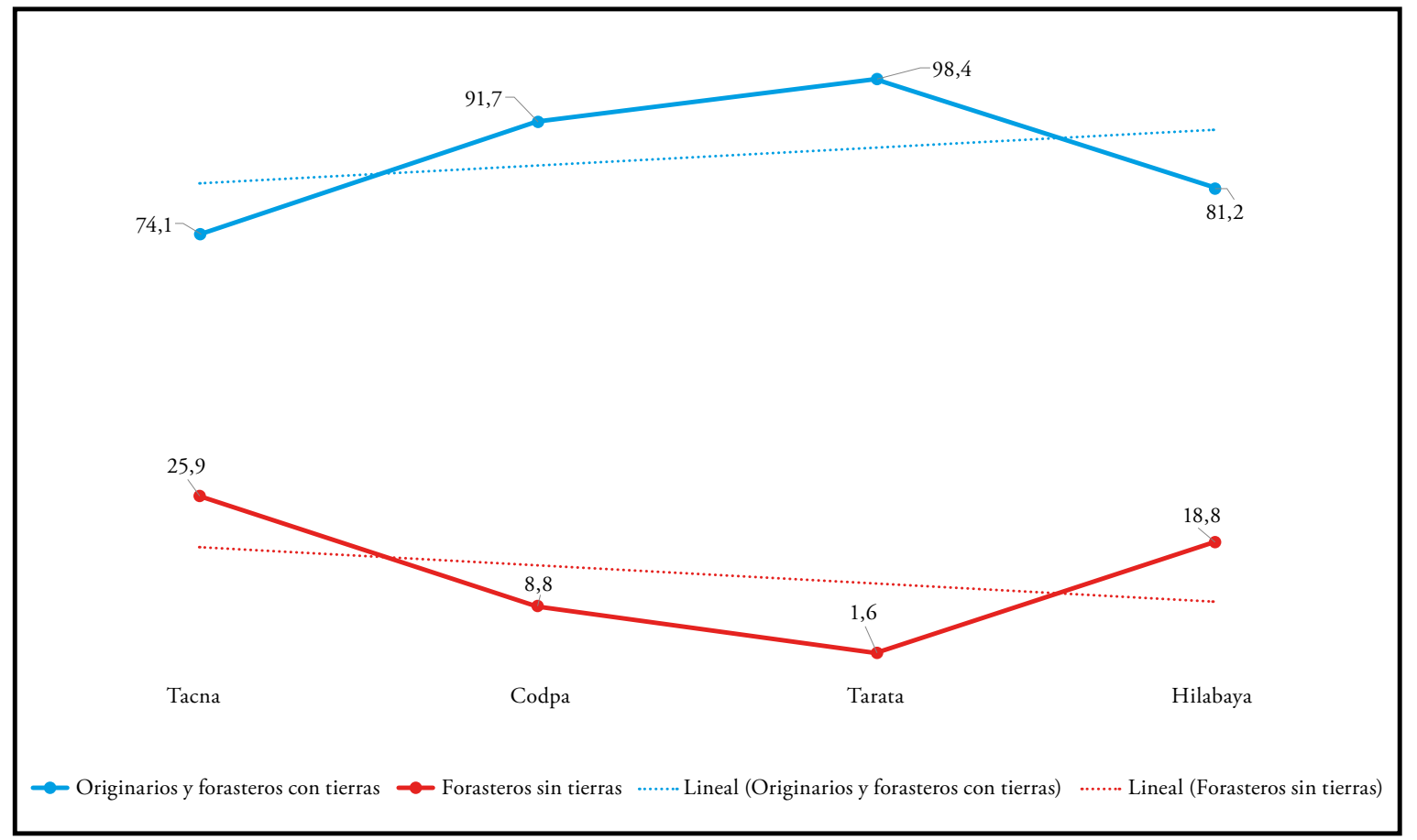

Figura 15. Porcentajes y tendencias de la población originaria/forastera en la visita de Antonio Álvarez y Ximénez, 1793.

los trabajos en las minas dada su rentabilidad y la especialización de dichos indios en los ingenios argentíferos. En este sentido, los oficios más rentables fueron los de barreteros, acarreadores o capacheros de metal, fogoneros y trabajadores de ingenios, que fueron considerados como una mano de obra privilegiada, y por tanto de gran libertad y movilidad (Sevilla, 1990; Medinacelli, 2010; Zagalsky, 2014). La existencia de una mayor presencia caranga en el siglo XVIII en los Altos de Arica fue temporal y se explica por su recuperación demográfica y no por el descenso del precio de la plata, puesto que pudieron redireccionar el excedente de su mano de obra a la agricultura en los valles costeros, ya que para los años 1772- 1775, la producción argentífera de Charcas alcanzó un $67,9 \%$ del total del Virreinato del Perú (Brown, 2015). Por tanto, no es posible evidenciar una continuidad cultural caranga en los valles y oasis occidentales, debido a la merma de esta población altiplánica producto de las epidemias, desastres naturales y la incesante demanda de jornaleros en los centros mineros, lo cual motivó que en ciertas décadas los carangas optasen por migrar a otras regiones donde la valorización económica de su mano de obra era mucho más alta que en Arica; situación que motivó el abandono de ciertos espacios productivos y los posteriores conflictos con el Cacicazgo de Codpa, produciéndose una ruptura de las interacciones culturales y rituales carangas, ${ }^{56}$ puesto que los antiguos colonos, por opción propia o coacción, asumieron la expresiones, identidades y cultura de las poblaciones locales.

La proporcionalidad de la coexistencia de originarios y forasteros no posee cambios sustantivos en la década de 1790 cuando el 70,2\% de la población de los partidos de Arica y Tacna es indígena, siguiendo la tendencia y prevalencia de una mayor cantidad de originarios en relación a los forasteros (Figura 15).

56 Viviana Yaccuzzi sostiene que desde la antropología la interacción permite desarrollar pensamientos, actitudes y responsabilidades compartidas; esto a su vez nos conduce a replantear las nociones de vida, existencia e inteligencia. Al compartir pensamientos y actitudes, lo que se vuelve en extremo importante es atesorar lo que cada uno piensa y hace ya que la interacción construye la dimensión del 'nosotros', un estado que saca al hombre del encierro del "yo" y hace que comprenda el valor de la cooperación en la red de conexiones que se produce en su entorno (Yaccuzzi, 2016). 
Si bien la población de Arica y Tacna solo representa el 13\% del total de la provincia de Arequipa, los cacicazgos mencionados evidencian una sustantiva recuperación demográfica. La existencia de los forasteros "con y sin tierra" constituye un esfuerzo de las autoridades virreinales por establecer nuevas categorías fiscales, puesto que para el siglo XVIII estos indígenas también están incluidos en las tasas de cada territorio desde 1735 (Saignes, 1987; Sica, 2014).

Los forasteros sin tierra ejercen diversas labores, tales como capataz, ovejero, arriero, quesero o peón, perpetuándose así su condición subalterna, ya que se diferenció de aquellos migrantes andinos que habían accedido a la tierra según diversas estrategias sociales y culturales. Dichas maniobras permitieron en algunas regiones andinas convertir a los forasteros en arrenderos de pequeńas chacras o parcelas. Finalmente, el estatus de afuerino involucra la existencia de tensiones y contradicciones en las comunidades andinas, puesto que se releva la cuestión del “otro", la marginalidad y diferenciación social entre los indígenas del área septentrional de los cacicazgos del Corregimiento de Arica.

\section{Reflexiones finales}

En 1532 se iniciaron profundas transformaciones socioculturales, económicas y políticas en el mundo andino como consecuencia de la implementación rigurosa de encomiendas, doctrinas y reducciones de indios, adquiriendo así forma el régimen colonial bajo la firme gestión de Francisco de Toledo y sus sucesores. Arica y Tacna no fueron ajenas a la metamorfosis a pesar de su localización periférica, ya que las ordenanzas del virrey Toledo convirtieron la región en el eje de la articulación económica y política entre Lima y Potosí, influenciando de manera notoria a las poblaciones locales insertas en el entorno del sistema vial del azogue y la plata.

El propósito del trabajo ha sido evidenciar los efectos de la política colonial en las poblaciones indígenas de la región, basándose en el estudio y análisis de cédulas, tasas y revisitas que dieron origen a la configuración del binomio originario/forastero. El surgimiento de la otredad colonial e indígena se for- jó bajo principios de identidad, economía y política, que buscaron el beneficio del Patrimonio Regio e interés de los curacas de la región.

La promoción de la relación de la Corona y señores étnicos se funda en la administración de la mano de obra indígena y usufructo de las tierras comunales, forjando con ello una nueva élite nativa en desmedro del poder de los encomenderos, mineros y hacendados. Dicha élite indígena local fue fundamental, tanto para la gestión de trabajos agrícolas como para la recaudación de los reales tributos, organización de las mitas en haciendas y minas del corregimiento. Asimismo, los pueblos de indios locales y sus curacas adquirieron un renovado prestigio social, capacidad de negociación e influencia en la sociedad colonial, a diferencia de los indios forasteros o agregados, que poseyeron un estatus inferior, no logrando participar en las relaciones de reciprocidad y negociación colonial. Las motivaciones del abandono de las reducciones fueron diversas, algunas de las cuales se debieron al sistema de explotación impuesto por encomenderos y mineros, epidemias o venta de su fuerza laboral en otros espacios, y en otros casos, a los efectos de los cambios ideológicos y culturales. En fin, fueron las disposiciones económicas y políticas del sistema de encomiendas y visitas generales las que dieron origen al indio forastero. El resultado de tales construcciones coloniales se extendió hasta nuestros días, puesto que pertenecer a un linaje o comunidad histórica-originaria conlleva un mayor prestigio social y cultural frente a indígenas inmigrantes contemporáneos, ello a pesar de estar insertos en espacios transfronterizos de permanente interacción y asimilación sociocultural.

Las convulsiones demográficas y mengua de los naturales alcanzó un 36\% entre 1540 y 1570 . La regulación de tasas y tratamiento de los indios amortizó levemente la caída en 1618, pues fray Vásquez de Espinoza evidencia una disminución de un 32,6\% de los indios tributarios. Semejantes contracciones obligaron a los señores étnicos del altiplano a desarrollar extensos pleitos por la recuperación de mittanis y tierras. El resultado final de tales demandas fue adverso, debido a la complicidad de las autoridades hispanas e indios de la costa, que aprovecharon la naturalización y recategorización de los indios foráneos para acceder a su mano de obra y tributos. 
Estos nuevos indios originarios pasaron a ser parte sustancial de las categorías fiscales; no obstante, su naturalización no fue meramente censal y tributaria para el caso de los huidos de otros repartimientos, puesto que se enfrentaron a la deconstrucción de sus ciclos rituales y culturales y, en este contexto, debieron adquirir y reproducir la cultura local para acceder a los recursos comunales como la tierra y agua. Por tanto, los forasteros generaron nuevos lazos de pertenencia, rasgos de identidad y adscripciones a estructuras comunales de los cacicazgos locales, compartiendo de esta manera las obligaciones socioculturales y económicas de los originarios. Un ejemplo de estas dinámicas se observó todavía en la década de 1980 en los Altos de Arica, donde los recién casados y forasteros debían participar del sistema de cargos religiosos comunales y tomar las mayordomías para acceder a tierras, turnos de riego y eximirse de algunos trabajos comunitarios.

Las revisitas de 1750 y 1772, no solo expusieron información estadística, etaria y tributaria de los cacicazgos de Codpa, Tarata e Hilabaya. Si bien el propósito de las visitas era el establecimiento de nuevos repartos y reales tributos, también permitieron identificar una mayor prevalencia de mujeres en los tres cacicazgos, situación que ya había evidenciado Jorge Hidalgo para el caso de Arica. Del mismo modo, se devela una ampliación de las categorías de la población censada, puesto que se incluyó a las distintas castas no hispanas en los registros de población. Esta situación permite establecer cuantitativamente la presencia de forasteros provenientes de tres antiguos señoríos altiplánicos dispersa en el corregimiento. Los primeros, ligados al espacio lupaca, se encuentran mayoritariamente en Tarata, con un $77,5 \%$ e Hilabaya que posee un $61,2 \%$. Una situación distinta se observa en el Cacicazgo de Co$\mathrm{dpa}$, que ostenta forasteros carangas que suman el $65,5 \%$; seguidos por el $8,8 \%$ de migrantes provenientes de la zona pacaje y solo el 1,2\% del espacio lupaca. La distribución espacial de los forasteros en Codpa y sus pueblos anexos coincide con las áreas de influencia de los señoríos aymara de inicios del siglo XVI, pues según las revisitas los forasteros carangas estaban localizados en la parte media y meridional del cacicazgo, mientras que los pacajes se situaron al norte del mencionado cacicazgo colonial.
En consecuencia, las reformas toledanas y borbónicas en los Andes forjaron una construcción taxonómica del originario/forastero y el "otro" en las poblaciones indígenas, generando con ello efectos adversos y oposiciones culturales entre la población local y migrante. Así los forasteros, mediante la naturalización, adscripción cultural y residencial, alianzas matrimoniales con originarias con tierra y relaciones de parentesco, engrosaron la población local, dando con ello continuidad cultural a los cacicazgos de los Altos de Arica y Tacna, incrementando de esta manera el Patrimonio Regio, la población y la identidad cultural costera.

\section{Agradecimientos}

Este trabajo ha sido elaborado en el marco de los proyectos FONDECYT 1191817 y UTA MAYOR 5772-19. Además, agradecemos los comentarios de Marco Curatola, Nathan Wachtel, Jan Szeminski, Alejandro Diez, Rodolfo Cerrón-Palominos, Bruce Mannheim, Steven Kosiba, Adam Herring y demás participantes del Seminario Interdisciplinar Pisac 2018, organizado por el Programa de Estudios Andinos de la Pontificia Universidad Católica del Perú, donde se presentó la ponencia. La gratitud que se extiende a los colegas y evaluadores por sus comentarios y sugerencias en miras del perfeccionamiento de este escrito. Asimismo, agradecemos a los vecinos del antiguo Cacicazgo de Codpa por la preservación de sus memorias y ritualidades, que nos permitieron conocer las pertenencias y significados de ser originarios. Gracias a Mario Choque, Victoria Sánchez $(\dagger)$, Neri Choque $(\dagger)$, María Carrasco, Eusebio Marca, Isidoro Flores, Patricia Carrasco, Marcelina Canavire y Liborio Gutiérrez $(\dagger)$ por los significados y significantes de la identidad y pertenencia originaria.

\section{Referencias citadas}

\footnotetext{
Albiez-Wieck, S. (2017). Indigenous migrants negotiating belonging: Peticiones de cambio de fuero in Cajamarca, Peru, 17th-18th centuries. Colonial Latin American Review, 26(2), 483-508.
}

Apey, M. (1990). Arica: Enclave costero del circuito comercial. Lima - Charcas (1545 - 1700). En Bravo, G. (Ed.). 
Economia y comercio en América hispana (pp. 15-35). Santiago: Universidad de Chile.

Araya, M. (2003). Fiscalidad y economía regional: Arica 1759-1799. Chungara. Revista de Antropología Chilena, 35(1), 141-157.

Assadourian, C. (1982). Sistema de la economía colonial. El Mercado interno, regiones y espacio económico. Lima: Instituto de Estudios Peruanos.

Assadourian, C. (1989). Acerca del cambio en la naturaleza del dominio sobre las indias: la mit'a minera del virrey Toledo, documentos de 1568-1571. Anuario de Estudios Americanos, 13, 70-90.

Bittmann, B. (1984). Interrelaciones étnicas establecidas a lo largo de la costa del norte de Chile y sur de Perú en el contexto de la colonia: Los camanchacas. Estudios Atacameños, 7, 327-334.

Brown, K. (2015). Minería e imperio en Hispanoamérica colonial. Producción, mercados y trabajo. Lima: Ediciones Banco Central de Reserva del Perú.

Cañedo-Argüelles, T. (1993). Potosí: la versión aymara de un mito europeo: la minería y sus efectos en las sociedades andinas del siglo XVII (la provincia de Pacajes). Madrid: Catriel.

Cañedo-Argüelles, T. (1995). Las reducciones indígenas en el sur andino: estrategias de producción y sus efectos en el medio ambiente. Revista complutense de historia de América, 21, 123-140.

Cañedo-Argüelles, T. (2005). La visita de Juan Gutiérrez Flores al Colesuyo y Pleitos por los cacicazgos de Torata y Moquegua. Lima: Editorial PUCP.

Carcelén, G. (2011). La visión ilustrada de los desastres naturales en Lima durante el siglo XVIII. Revista Colombiana de Geografía, 20(1), 55-64.

Casassas, J. (1974). Algunas noticias sobre los partidos de Arica y Tarapacá hacia fines del siglo XVIII y principios del XIX. Norte Grande, 1(2), 217-227.

Castro, I. y Palomeque, S. (2016). Originarios y forasteros del sur andino colonial. América Latina en la Historia Económica, 23(3), 37-79.
Cavagnaro, L. (1988). Materiales para la historia de Tacna. Tomo II. Tacna: CMT.

Cavagnaro, L. (2005). Materiales para la historia de Tacna. Tomo V. Tacna: CMT.

Cerrón Palominos, R. (2011). El legado onomástico puquina. A propósito de Cápac Yupanqui. Estudios Atacameños. Arqueologia y Antropología Surandinas, 41, 119-130.

Charney, P. (2001). Indian society in the Valley of Lima, Perú, 1532 - 1824. Lanham: University Press of America.

Chirinos, A. y Zegarra, M. (2013). El orden del Inca. Lima: Editorial Comentarios.

Choque, C. (2009). Memoria y olvido del pueblo de Socoroma. Deconstruyendo su historia e identidad. Arica: Tierra Viva.

Choque, C. (2015). Los Socoromas. Modos de vida, tecnología y religiosidad. Arica: Ediciones CONADI - Tierra Viva.

Choque, C. y Pizarro, E. (2009). El Colesuyu meridional: Espacio de articulación económica y cultural hispanoindígena en el siglo XVI. Allpanchis, 73/74, 241-268.

Choque, C. y Pizarro, E. (2013). Identidades, continuidades y rupturas en el culto al agua y a los cerros en Socoroma, una comunidad andina de los Altos de Arica. Estudios Atacameños. Arqueología y Antropología Surandinas, 45, 55-74.

Choque, C. y Muñoz, I. (2016). El camino real de la plata. Circulación de mercancías e interacciones culturales en los valles y altos de Arica (siglos XVI al XVIII). Historia, 49(1), 57-86.

Contreras, C. (2001). Haciendas y comunidades indias en la región andina durante el siglo XVIII. En Garrido, M. (Ed.), Historia América andina. Sistema colonial tardio (pp. 87-116). Quito: Universidad Andina Simón Bolívar.

Cook, N. (1975). Tasa de la visita general de Francisco de Toledo. Lima: UNMSM.

Cook, N. (2002). Avances en el estudio de la población andina colonial. Histórica, XXVI(1-2),15-81.

Cook, N. (2005). La conquista biológica: las enfermedades del Nuevo Mundo. Madrid: Siglo XXI. 
Cook, N. (2010). La catástrofe demográfica andina. Perú 1520-1620. Lima: Editorial PUCP.

Cuneo-Vidal, R. (1977a). Obras completas. Cacicazgos del sur del Perú. Lima: Gráfica Morsom.

Dagnino, V. (1909). El Correjimiento de Arica. Arica: Imprenta La Época.

Durston, A. (2000). El proceso reduccional en el sur andino: confrontación y síntesis de sistemas espaciales. Revista Historia Indigena, 4, 75-102.

Durston, A. e Hidalgo, J. (1997). La presencia andina en los valles de Arica, siglos XVI-XVIII. Casos de regeneración colonial de estructuras archipielágicas. Chungara, Revista de Antropología Chilena, 29(2), 249-273.

Escobari, L. (2012). Mano de obra especializada en los mercados coloniales de Charcas, Bolivia (siglos XVI-XVII). Estudios Bolivianos, 16, 55-82.

Espinosa Soriano, W. (1964). Visita hecha a la provincia de Chucuito por Garci Diez de San Miguel en el año 1567. Lima: Talleres Graficos Quiros.

Estenssoro, J. C. (2003). Del paganismo a la santidad. La incorporación de los indios del Perú al catolicismo, 15321750. Lima: PUCP - IFEA.

Galdos, G. (1982). Uros, Camanchacas, Changos, Puquinas y yungas pescadores en Sud-Perú y Norte de Chile. Diálogo Andino, 1, 14-29.

Gareis, I. (2008). Los rituales del Estado colonial y las élites andinas. Bulletin de l'Institut Français d'Études Andines, 37(1), 97-109.

Gavira, M. (2008). Población indigena, sublevación y minería en Carangas (Bolivia), 1750-1804. Lima: Ediciones IFEA - UTA.

Gavira, M. (2010). La población del corregimiento de Carangas (Virreinato del Río de La Plata) a fines del siglo XVIII. América Latina en la Historia Económica, 17(1), 65-89.

Gil, F. y Fernández, G. (2008). El culto a los cerros en el mundo andino (dossier monográfico). Revista Española de Antropología Americana, 38(1), 105-113.

Gil Montero, R. (2014). Mecanismos de reclutamiento indígena en la minería de plata: Lípez (sur de la actual Boli- via), siglo XVII. América Latina en la historia económica, 21(1), 5-30.

Gil Montero, R., Rivet, C. y Longhi, F. (2017). Las visitas coloniales y los espacios internodales a fines del siglo XVII: propuestas para la interpretación de sus silencios. Estudios Atacameños. Arqueología y Antropología Surandinas, 56, 273-297.

Glave, L. M. (2000). Intercambio y productos de comercio. En Pease, F. (Ed.). Historia general de América Latina, Tomo II. (pp. 391-404). Madrid: Ediciones UNESCO Editorial Trotta.

Glave, L. M. y Díaz, A. (2019). Buscando al encomendero. Lucas Martínez Vegaso, la administración de la justicia y las redes del poder colonial. Tarapacá, siglo XVI. Estudios Atacameños. Arqueología y Antropología Surandinas, 61, 155-176.

Golte, J. (1980). Repartos y rebeliones: Túpac Amaru y las contradicciones de la economía colonial. Lima: Instituto de Estudios Peruanos.

Hampe, T. (1985). Visita de los indios originarios y forasteros de Paucarcolla en 1728. Revista Española de Antropología Americana, XV, 209-240.

Herrera, J. (1997). El amanecer de Arica y Tarapacá en el siglo $X V I-X V I I I$. Iquique: Ediciones IECTA.

Hidalgo, J. (1978). Revisita a los Altos de Arica efectuada por el oficial real don Joaquín de Cárdenas, 1750. Iquique: Universidad del Norte.

Hidalgo, J. (1984b). Descomposición cultural en Atacama en el siglo XVIII: Lengua, escuelas, fugas y complementariedad ecológica. Simposio Culturas Atacameñas (pp. 221-249). $44^{\circ}$ Congreso de Americanistas. Antofagasta: Universidad del Norte

Hidalgo, J. (2004). Historia andina en Chile. Santiago: Editorial Universitaria.

Hidalgo, J. y Focacci, G. (1986). Multietnicidad en Arica, siglo XVI. Evidencias etnohistóricas y arqueológicas. Chungara, 16/17, 137-147.

Hidalgo, J., Arévalo, P., Marsilli, M. y Santoro, C. (1988). Padrón de la Doctrina de Belén en 1813: Un caso de complementariedad tardia. Arica: Universidad de Tarapacá. 
Hidalgo, J. y Durston, A. (1998). Reconstitución étnica colonial en la sierra de Arica: El Cacicazgo de Codpa, 1650 - 1780. En Actas del IV Congreso Internacional de Etnohistoria. Tomo II (pp. 34-75). Lima: Editorial PUCP.

Hidalgo, J., Castro, N. y González, S. (2004b). La revisita de Codpa (Altos de Arica) de 1772-73 efectuada por el corregidor Demetrio Egan. Chungara. Revista de Antropología Chilena, 36(1), 103-204.

Horta, H. (2010). El señorío Arica y los reinos altiplánicos: Complementariedad ecológica y multietnicidad durante los siglos de pre-conquista en el norte de Chile (1.000 - 1.540 d.C.). Santiago: Qillqa, Universidad Católica del Norte - Ocho Libros.

Horta, H. (2011). El gorro troncocónico o chucu y la presencia de población altiplánica en el norte de Chile durante el Período Tardío (ca. 1.470-1.536 d.C.). Chungara. Revista de Antropología Chilena, 43(1), 551-580.

Horta, H. (2013). Queros de madera del Collasuyo: Nuevos datos arqueológicos parar definir tradiciones (S.XIVXVI). Estudios Atacameños. Arqueología y Antropología Surandinas, 45, 95-116.

Horta, H. y Agüero, C. (2009). Estilo, iconografía y función de las inkuńas prehispánicas del norte de Chile durante el período Intermedio Tardío (1.000-1.470 d.C.). Chungara. Revista de Antropología Chilena, 41(2), 183-227.

Huertas, L. (2009). Injurias del Tiempo. Desastres naturales en la Historia del Perú. Lima: Universidad Ricardo Palma.

Inostroza, X. (2013). Dimensiones del liderazgo étnico en el pueblo de Belén: Francisco Ocharan, secretario del cabildo indígena: Altos de Arica (1750-1813). Estudios Atacameños. Arqueología y Antropología Surandinas, 46, $109-126$.

Inostroza, X. (2014). Matrimonio y familia en sociedades andinas: propuestas desde la reconstitución de familias de Santiago de Tacrama o Belén. Altos de Arica, Virreinato del Perú (1763-1820). Historia, 47(1), 65-90.

Julien, K. (1979). Koli: A language spoken on the Preuvian Coast. Andean Perspective Newsletter, 3, 45-65.

Julien, K. (1983). Hatuncolla: A View of Inca Rule from the Lake Titicaca Region. University of California Publications in Anthropology, 15, 22-82.
Kessel, J. (2003a). Holocausto al progreso: Los aymaras de Tarapacá. Iquique: Ediciones IECTA.

Larraín, H. (1974). Población indígena de Tarapacá (norte de Chile), entre 1538 y 1581. Norte Grande, 1(3-4), 269-300.

Larson, B. (2017). Colonialismo y Transformación Agraria. Cochabamba, 1550-1900. La Paz: Biblioteca para el Bicentenario.

Laviana. M. (1983). Perú y Charcas. Madrid: Ediciones RIALP.

Livi Bacci, M. (2007). A Concise History of World Population. Oxford: Blackwell Publishing.

Lohmann Villena, G. (1986). Francisco de Toledo. Disposiciones gubernativas para el virreinato del Perú. Sevilla: EEHA - CSIC.

Marchena, J. (2005). Su Majestad quiere saber. Información oficial y reformismo borbónico: El mundo andino bajo la mirada de la ilustración. Procesos, 22, 45-83.

Marsilli, M. y Cisternas, P. (2010). Los senderos de la idolatría: el viaje de Vázquez de Espinosa por los altos de Arica, 1618. Chungara. Revista de Antropología Chilena, 42(2), 465-476.

Martínez, J. (2012). El virrey Toledo y el control de las voces andinas coloniales. Colonial Latin American Review, 21(2), 175-208.

Medinacelli, X. (2010). Sariri. Los llameros y la construcción de la sociedad colonial. La Paz: Ediciones Plural - IEB.

Merluzzi, M. (2014). Gobernando los Andes. Francisco de Toledo virrey del Perú (1569-1581). Lima: Fondo Editorial PUCP.

Morrone, A. (2017). El lago de los curas: mediación sociopolítica y cultural en los corregimientos del lago Titicaca (1570-1650). Estudios Atacameños. Arqueología y Antropologia Surandinas, 55, 183-202.

Muñoz, I. (1989). Perfil de la organización económica social en la desembocadura del río Camarones. Período Intermedio Tardío e Inca. Chungara. Revista de Antropología Chilena, 22, 85-112.

Muñoz, I. y Choque, C. (2013). Interacción y cambio social: Un relato arqueológico e histórico sobre las poblaciones 
que habitaron los valles precordilleranos de Arica durante los siglos X al XVII d.C. Historia, 46(2), 421-441.

Murra, J. (1964). Una apreciación etnológica de la visita. En Espinoza, W. (Ed.). Visita hecha a la provincia de Chucuito por Garci Diez de San Miguel en el año 1567 (pp. 419-444). Lima: Casa de la Cultura del Perú.

Murra, J. (1972). El control vertical de un máximo de pisos ecológicos en la economía de las sociedades andinas. Huánuco: Universidad Nacional Hermilio Valdizán.

Murra, J. (2002). El mundo andino. Población, medio ambiente y economía. Lima: Editorial PUCP.

Paz Soldán, E. (1984). La intendencia de Arequipa organización y problemas económicos. Histórica, VII(2), 151175.

Pearce, A. (2001). The Peruvian Population Census of 1725-1740. Latin American Research Review, 36 (3), 69104.

Platt, T. y Quisbert, P. (2010). Tras las huella del silencio: Potosí, los incas y Toledo. Runa, 31(2), 115-152.

Polo de Ondegardo, J. (1916). Religión y Gobierno de los Incas. Lima: Imprenta y Librería Sanmarti Ca.

Presta, A. (2008). La primera joya de la Corona en el Altiplano Surandino. Descubrimiento y explotación de un yacimiento minero inicial: Porco, 1538-1576. En Cruz, P., Vacher, J. (Eds.). Minas y Metalurgia en los Andes del Sur. Desde la época prehispánica hasta el siglo XVII (pp. 301-320). Sucre: IFEA - CNRS-MAEE.

Rivière, G. (1982). Sabaya: Structures socio-économiques et represéntations symboliques dans le Carangas - Bolivie. Paris: École des Hautes Études en Sciences Sociales.

Robinson, D. (2006). Collaguas III: Yanque Collagua. Sociedad, economía y población, 1604 - 1617. Lima: Editorial Pontificia Universidad Católica del Perú - Syracuse University.

Rostworowski, M. (1986). La región del Colesuyo. Chungará, 16/17, 127-136.

Rothhammer, F., Moraga, M., Santoro, C., y Arriaza, B. (2010). Origen de los Changos. Análisis de ADNmt antiguo sugiere descendencia de pescadores de la cultura
Chinchorro (7.900 - 4.000 A.P.). Revista Med Chile, 138, 251-256.

Ruz, R., Díaz, A., y Galdames, L. (2008). Población Andina de las Provincias de Arica y Tarapacá. El Censo Inédito de 1866. Arica: Ediciones Universidad de Tarapacá.

Saignes, T. (1985). Los Andes Orientales: Historia de un Olvido. Cochabamba: Ceres.

Saignes, T. (1987). Ayllus, mercado y coacción colonial: el reto de las migraciones internas en Charcas (Siglo XVII). En Harris, O., Larson, B. y Tandeter, E. (Eds.). La participación indigena en los mercados surandinos: estrategias $y$ reproducción social, siglos XVI a XX (pp. 111-158). La Paz: Centro de Estudios de la Realidad Económica y Social.

Saignes, T. (1991). Lobos y ovejas. Formación y desarrollo de los pueblos y comunidades en el Sur Andino (Siglos XVI - XX). En Moreno, S. y Salomon, F. (Eds.). Reproducción y transformación de las sociedades andinas, siglos $X V I-X X$ (pp. 91-135). Quito: Ediciones Abya-Yala.

Saito, A. y Rosas, C. (2017). Reducciones. La concentración forzada de las poblaciones indigenas en el Virreinato del Perú. Lima: Editorial PUCP.

Saldarriaga, G. (2017). Trabajo y vida indígenas en los trapiches del Nuevo Reino de Granada, 1576 - 1674. História e Cultura Material, 25(1), 149-168.

Sanhueza, C. (2008a). "Indios" de los Oasis, "Indios" de la Puna. Procesos Migratorios y rearticulaciones identitarias en Atacama (Susques, siglos XVIII-XIX). Chungara. Revista de Antropología Chilena, 40(2), 203-217.

Sanhueza, C. (2008b). Territorios, prácticas rituales y demarcación del espacio en Tarapacá en el siglo XVI. Boletín del Museo Chileno de Arte Precolombino, 13(2), 57-75.

Serulnikov, S. (2003). De forasteros a hilacatas: una familia andina de la provincia de Chayanta, siglo XVIII. Jahrbuch fü Geschichte Lateinamerikas, 40, 43-70.

Sevilla, R. (1990). La minería americana y la crisis del siglo XVII. Estado del problema. Historiografía y Bibliografia, $2,61-81$.

Sica, G. (2014). Forasteros, originarios y propietarios en la quebrada de Humahuaca, Jujuy (siglos XVII y XVIII). Estudios sociales del NOA, 14, 15-39. 
Tandeter, E. y Wachtel, N. (1983). Precio y producción agraria. Potosi y Charcas siglo XVIII. Buenos Aires: Editorial Ceres.

Tell, S. y Castro, I. (2016). Los pueblos de indios de Córdoba del Tucumán y el pacto colonial (Siglos XVII a XIX). Revista del Museo de Antropología, 9 (2), 209-220.

Torero, A. (1987). Lenguas y pueblos altiplánicos en torno a 1 siglo XVI. Estudios y Debates, 2, 329-405.

Trelles, E. (1991). Lucas Martínez Vegazo: Funcionamiento de una encomienda peruana inicial. Lima: Editorial PUCP.

Vázquez de Espinosa, A. (1948). Compendio y descripción de las Indias occidentales. Washington, DC: Smithsonian Institution.

Wachtel, N. (1992). Dioses y vampiros. Regreso a Chipaya. México: Fondo de Cultura Económica.
Walker, C. (2003). The Upper Classes and Their Upper Stories: Architecture and the Aftermath of the Lima Earthquake of 1746. Hispanic American Historical Review, 83(1), 53-82.

Watanabe, W., Moseley, M. y Cabieses, F. (1990). Trabajos Arqueológicos en Moquegua. Programa del Contisuyo. Lima: Southern Perú Copper Corporation.

Wightman, A. (1990). Indigenous migration and social change: The forasteros of Cuzco, 1570 - 1720. Durham, NC: Duke University Press.

Yaccuzzi, V. (2016). Interacción: Noción que Impacta en Antropología y Actualiza el Concepto de Hombre. Rosebud-Arts, Critique, Journalism, 12(5), 1-5.

Zagalsky, P. (2014). Trabajadores indígenas mineros en el Cerro Rico de Potosí: tras los rastros de sus prácticas laborales (siglos XVI y XVII). Revista Mundos do Trabalho, 6(12), 55-82. 